Cochrane Database of Systematic Reviews

\title{
Peritoneal dialysis for acute kidney injury (Review)
}

Liu L, Zhang L, Liu GJ, Fu P

Liu L, Zhang L, Liu GJ, Fu P.

Peritoneal dialysis for acute kidney injury.

Cochrane Database of Systematic Reviews 2017, Issue 12. Art. No.: CD011457.

DOI: 10.1002/14651858.CD011457.pub2.

www.cochranelibrary.com 
TABLE OF CONTENTS

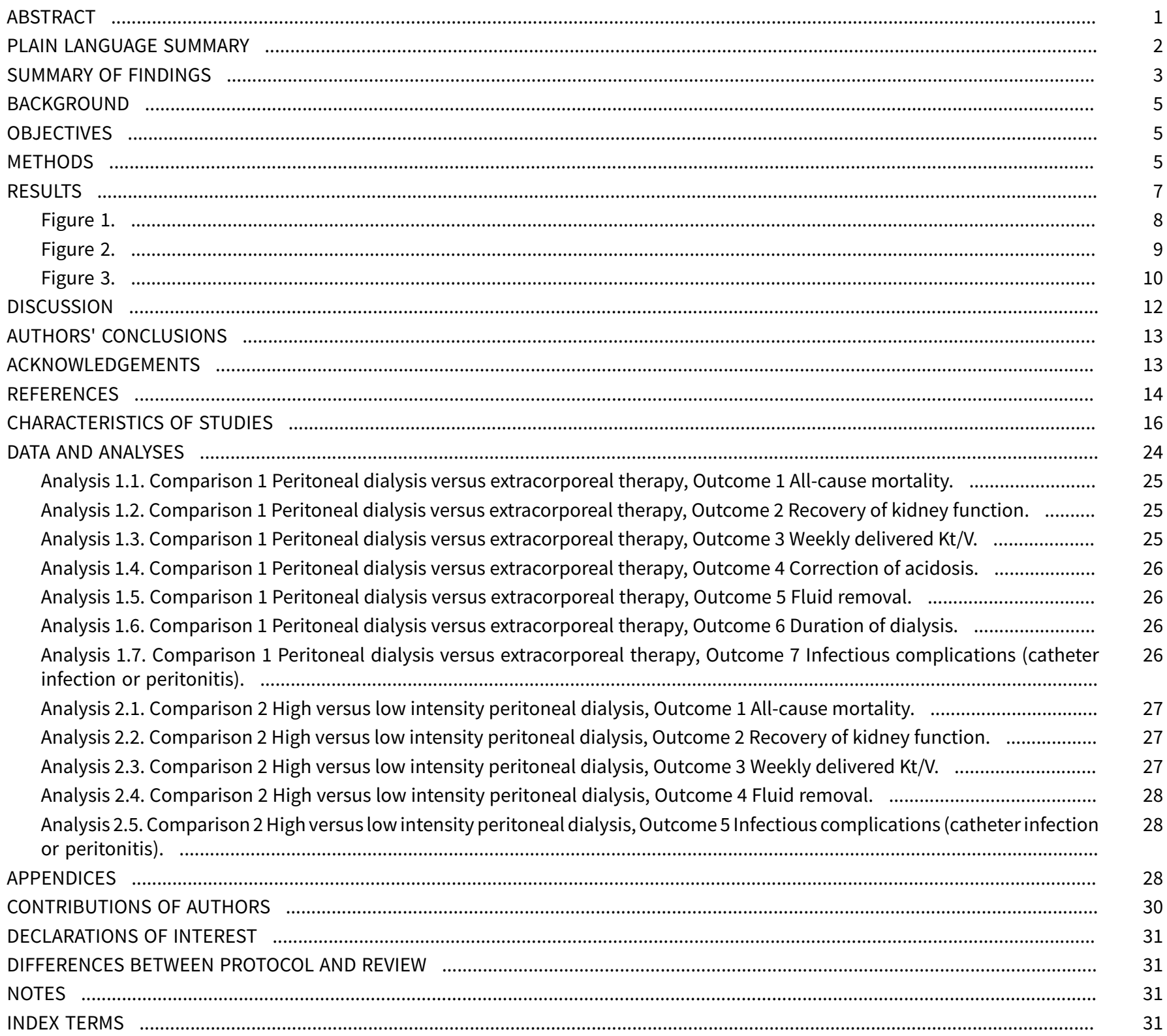


[Intervention Review]

\section{Peritoneal dialysis for acute kidney injury}

Linfeng Liu ${ }^{1}$, Ling Zhang ${ }^{1}$, Guan J Liu ${ }^{2}$, Ping Fu ${ }^{1}$

1Department of Nephrology, West China Hospital, Sichuan University, Chengdu, China. ${ }^{2}$ Cochrane China, West China Hospital, Sichuan University, Chengdu, China

Contact: Ling Zhang, Department of Nephrology, West China Hospital, Sichuan University, No. 37, Guo Xue Xiang, Chengdu, Sichuan, 610041, China.zhanglinglzy@163.com,6332111@qq.com.

Editorial group: Cochrane Kidney and Transplant Group.

Publication status and date: New, published in Issue 12, 2017.

Citation: Liu L, Zhang L, Liu GJ, Fu P. Peritoneal dialysis for acute kidney injury. Cochrane Database of Systematic Reviews 2017 , Issue 12. Art. No.: CD011457. DOI: 10.1002/14651858.CD011457.pub2.

Copyright (c 2017 The Cochrane Collaboration. Published by John Wiley \& Sons, Ltd.

\section{A B S T R A C T}

\section{Background}

Peritoneal dialysis (PD) has been suggested as an effective and safe dialysis modality in patients with acute kidney injury (AKI). However, whether PD is superior to extracorporeal therapy (e.g. haemodialysis) in terms of improving survival, recovery of kidney function, metabolic and clinical outcomes is still inconclusive.

\section{Objectives}

The aim of this review was to evaluate the benefits and harms of PD for patients with AKI compared with extracorporeal therapy or different PD modalities.

\section{Search methods}

We searched the Cochrane Kidney and Transplant Register of Studies to 29 May 2017 through contact with the Information Specialist using search terms relevant to this review. Studies in the Register are identified through searches of CENTRAL, MEDLINE, and EMBASE, conference proceedings, the International Clinical Trials Register (ICTRP) Search Portal, and ClinicalTrials.gov. We also searched the China Biological Medicine Database.

\section{Selection criteria}

We included patients with AKI who were randomised to receive PD, extracorporeal therapy, or different PD modalities regardless of their age, sex, primary disease and clinical course.

\section{Data collection and analysis}

Screening, selection, data extraction and quality assessments for each retrieved article were carried out by two authors using standardised forms. Authors contacted when published data were incomplete. Statistical analyses were performed using the random effects model and results expressed as risk ratio (RR) with $95 \%$ confidence intervals $(\mathrm{Cl})$. Heterogeneity among studies was explored using the Cochran $\mathrm{Q}$ statistic and the 12 test. Outcomes of interest included all-cause mortality, recovery of kidney function, weekly delivered Kt/V, correction of acidosis, fluid removal, duration of dialysis, and infectious complications. Confidence in the evidence was assessing using GRADE.

\section{Main results}

Six studies (484 participants) met our inclusion criteria. Five studies compared high volume PD with daily haemodialysis, extended daily haemodialysis, or continuous renal replacement therapy. One study focused on the intensity of PD. The overall risk of bias was low to unclear. Compared to extracorporeal therapy, PD probably made little or no difference to all-cause mortality (4 studies, 383 participants: RR $1.12,95 \% \mathrm{Cl} 0.81$ to $1.55 ; \mathrm{I}^{2}=69 \%$; moderate certainty evidence), or kidney function recovery ( 3 studies, 333 participants: RR 0.95 , $95 \%$ 
$\mathrm{Cl} 0.68$ to $1.35 ; \mathrm{I}^{2}=0 \%$; moderate certainty evidence). PD probably slightly reduces the amount of fluid removal compared to extracorporeal therapy ( 3 studies, 313 participants: MD $-0.59 \mathrm{~L} / \mathrm{d}, 95 \% \mathrm{Cl}-1.19$ to $0.01 ; \mathrm{I}^{2}=89 \%$; low certainty evidence), and probably made little or no difference to infectious complications ( 2 studies, 263 participants: RR $1.03,95 \% \mathrm{Cl} 0.60$ to $1.78 ; \mathrm{I}^{2}=0 \%$; low certainty evidence). It is uncertain whether PD compared to extracorporeal therapy has any effects on weekly delivered Kt/V (2 studies, 263 participants: MD -2.47, $95 \% \mathrm{Cl}-5.17$ to $0.22 ; \mathrm{I}^{2}=99 \%$; very low certainty evidence), correction of acidosis ( 2 studies, 89 participants: $\mathrm{RR} 1.32,95 \% \mathrm{Cl} 0.13$ to 13.60 ; $\mathrm{I}^{2}=96 \%$; very low certainty evidence), or duration of dialysis ( 2 studies, 170 participants: MD -1.01 hours, $95 \% \mathrm{Cl}-91.49$ to $89.47 ; \mathrm{I}^{2}=98 \%$; very low certainty evidence). Heterogeneity was high and this may be due to the different extracorporeal therapies used.

One study (61 participants) reported little or no difference to all-cause mortality, kidney function recovery, or infection between low and high and intensity PD. Weekly delivered Kt/V and fluid removal was lower with low compared to high intensity PD.

\section{Authors' conclusions}

Based on moderate (mortality, recovery of kidney function), low (infectious complications), or very low certainty evidence (correction of acidosis) there is probably little or no difference between PD and extracorporeal therapy for treating AKI. Fluid removal (low certainty) and weekly delivered Kt/V (very low certainty) may be higher with extracorporeal therapy.

\section{PLAIN LANGUAGE SUMMARY}

\section{Peritoneal dialysis for acute kidney injury}

\section{What is the issue?}

Acute kidney injury (AKI) is an abrupt and usually reversible decline in the glomerular filtration rate. No particular form of renal replacement therapy (treatment that replaces the normal blood-filtering function of the kidneys) for patients with AKI has been clearly shown to have a benefit. The choice of renal replacement therapy is dependent upon a variety of factors including availability, the expertise of the clinician, haemodynamic stability and so on.

\section{What did we do?}

This review aimed to evaluate the benefits and harms of peritoneal dialysis (PD) for patients with AKI compared with extracorporeal therapy (e.g. haemodialysis) or other types of PD. We searched the Cochrane Kidney and Transplant Register of Studies.

\section{What did we find?}

Six randomised controlled trials (484 patients) met our inclusion criteria. Five studies compared high volume PD with daily haemodialysis, extended daily haemodialysis, or continuous renal replacement therapy, and one study compared different intensities of PD on AKI patients. Compared to extracorporeal therapy, PD probably made little or no difference to death due to any cause or recovery of kidney function. PD probably slightly reduces the amount of fluid removal compared to extracorporeal therapy, and probably made little or no difference to infectious complications. It is uncertain whether PD compared to extracorporeal therapy has any effects on weekly delivered $\mathrm{Kt} / \mathrm{V}$, correction of acidosis, or duration of dialysis.

One study (61 participants) reported little or no difference to death due to any cause, kidney function recovery, or infection between low and high and intensity PD. Weekly delivered Kt/V and fluid removal was lower with low compared to high intensity PD.

\section{Conclusions}

There is currently not enough evidence to determine whether there are significant differences in death due to any cause or recovery of kidney function between patients treated with PD, extracorporeal therapies, or intensity of PD. 
SUMMARY OF FINDINGS

Summary of findings for the main comparison. Peritoneal dialysis compared with haemodialysis for acute kidney injury

Peritoneal dialysis versus extracorporeal therapy for acute kidney injury

Patient or population: patients with acute kidney injury

Settings: inpatient

Intervention: peritoneal dialysis

Comparison: extracorporeal therapy

\begin{tabular}{|c|c|c|c|c|c|c|}
\hline \multirow[t]{3}{*}{ Outcomes } & \multicolumn{2}{|c|}{ Illustrative comparative risks* $(95 \% \mathrm{Cl})$} & \multirow{3}{*}{$\begin{array}{l}\text { Relative effect } \\
(95 \% \mathrm{CI})\end{array}$} & \multirow{3}{*}{$\begin{array}{l}\text { No. of partici- } \\
\text { pants } \\
\text { (studies) }\end{array}$} & \multirow{3}{*}{$\begin{array}{l}\text { Quality of the } \\
\text { evidence } \\
\text { (GRADE) }\end{array}$} & \multirow[t]{3}{*}{ Comments } \\
\hline & Assumed risk & Corresponding risk & & & & \\
\hline & Extracorporeal therapy & Peritoneal dialysis & & & & \\
\hline $\begin{array}{l}\text { All-cause mor- } \\
\text { tality }\end{array}$ & 542 per 1000 & $\begin{array}{l}607 \text { per } 1000 \\
(439 \text { to } 841)\end{array}$ & $\begin{array}{l}\text { RR } 1.12 \text { (0.81 to } \\
1.55)\end{array}$ & $4(383)$ & $\begin{array}{l}\oplus \oplus \oplus \ominus \\
\text { Moderate } 1\end{array}$ & $\begin{array}{l}\text { Downgraded for study limita- } \\
\text { tions }\end{array}$ \\
\hline $\begin{array}{l}\text { Recovery of } \\
\text { kidney func- } \\
\text { tion }\end{array}$ & 284 per 1000 & $\begin{array}{l}270 \text { per } 1000 \\
(193 \text { to } 384)\end{array}$ & $\begin{array}{l}\text { RR } 1.42 \text { ( } 0.74 \text { to } \\
2.75 \text { ) }\end{array}$ & $3(333)$ & $\begin{array}{l}\oplus \oplus \oplus \ominus \\
\text { Moderate } 1\end{array}$ & $\begin{array}{l}\text { Downgraded for study limita- } \\
\text { tions }\end{array}$ \\
\hline $\begin{array}{l}\text { Weekly deliv- } \\
\text { ered Kt/V }\end{array}$ & \multicolumn{2}{|c|}{$\begin{array}{l}\text { The mean delivered Kt/V was } 2.47 \text { lower ( } 5.17 \text { lower to } 0.22 \\
\text { higher) in the peritoneal dialysis group compared to the ex- } \\
\text { tracorporeal therapy group }\end{array}$} & & $2(263)$ & $\begin{array}{l}\oplus \odot \Theta \odot \\
\text { Very low } 1,2,3\end{array}$ & $\begin{array}{l}\text { Downgraded for study limita- } \\
\text { tions, imprecision and insuffi- } \\
\text { cient data }\end{array}$ \\
\hline $\begin{array}{l}\text { Correction of } \\
\text { acidosis }\end{array}$ & 577 per 1000 & $\begin{array}{l}762 \text { per } 1000 \\
(70 \text { to } 1,000)\end{array}$ & $\begin{array}{l}\text { RR } 1.32 \text { (0.1 to } \\
13.60)\end{array}$ & $2(120)$ & $\begin{array}{l}\oplus \odot \Theta \odot \\
\text { Very low } 1,2,3\end{array}$ & $\begin{array}{l}\text { Downgraded for study limita- } \\
\text { tions, imprecision and insuffi- } \\
\text { cient data }\end{array}$ \\
\hline $\begin{array}{l}\text { Fluid removal } \\
\text { (L/d) }\end{array}$ & \multicolumn{2}{|c|}{$\begin{array}{l}\text { The mean fluid removal was } 0.59 \mathrm{~L} / \mathrm{d} \text { lower }(1.19 \text { lower to } \\
0.01 \text { higher) in the peritoneal dialysis group compared to the } \\
\text { extracorporeal therapy group }\end{array}$} & & $3(313)$ & $\begin{array}{l}\oplus \oplus \oplus \ominus \\
\operatorname{Low}^{1,2}\end{array}$ & $\begin{array}{l}\text { Downgraded for study limita- } \\
\text { tions and imprecision }\end{array}$ \\
\hline $\begin{array}{l}\text { Duration } \\
\text { of dialysis } \\
\text { (hours) }\end{array}$ & \multicolumn{2}{|c|}{$\begin{array}{l}\text { The mean duration of dialysis was } 1.01 \text { hours less ( } 91.49 \text { low- } \\
\text { er to } 92.54 \text { higher) in the peritoneal dialysis group compared } \\
\text { to the extracorporeal therapy group }\end{array}$} & & $2(170)$ & $\begin{array}{l}\oplus \odot \Theta \odot \\
\text { Very low } 1,2,3\end{array}$ & $\begin{array}{l}\text { Downgraded for study limita- } \\
\text { tions, imprecision and insuffi- } \\
\text { cient data }\end{array}$ \\
\hline
\end{tabular}




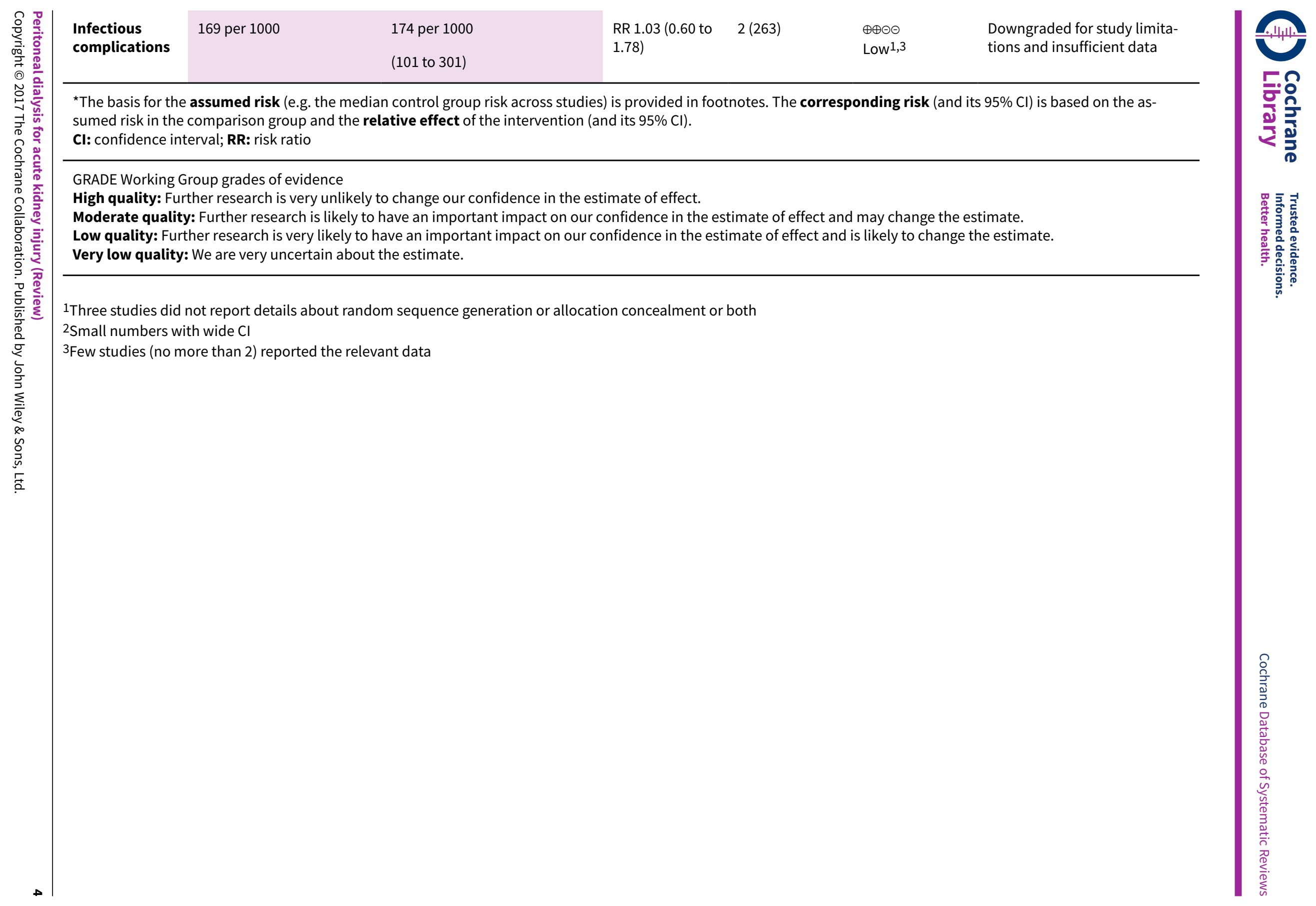




\section{B A C K G R O U N D}

\section{Description of the condition}

Acute kidney injury (AKI) is generally characterised by an abrupt deterioration in kidney function, with accumulation of creatinine, urea, metabolic acids, electrolytes, and decreased urine output. AKI is increasingly prevalent globally and associated with significant morbidity and mortality (Hoste 2006; Hsu 2013; Piccinni 2011). A systematic review, which included 49 million patients and 312 cohort studies, found that AKI occurred in 20\% adults and $33 \%$ of children who are hospitalised with acute illness. Mortality remains unacceptably high, unadjusted mortality associated with an episode of AKI has been estimated at $23.9 \%$ in adults and $13.8 \%$ in children (Susantitaphong 2013).

\section{Description of the intervention}

Extracorporeal therapy, including continuous renal replacement therapy (CRRT) and intermittent HD (IHD), is the most common therapies for the treatment of people with AKI. However, the effect of peritoneal dialysis (PD) for AKI remains unclear despite the use of PD preceding extracorporeal therapy for the treatment of AKI (Gabriel 2006). PD is a preferred dialysis option for most children with AKI, patients with vascular access failure, and those with unstable haemodynamics or who are at risk of bleeding (Ponce 2012). PD use has progressively declined in favour of extracorporeal therapy in many settings, particularly pump-assisted modes of dialysis (Bunchman 1994; Ellis 1997).

Although extracorporeal therapy is now the treatment of choice for most people with AKI, PD is still widely used in some settings (Gabriel 2007a; Ponce 2011). There is no randomised controlled trial (RCT) evidence to indicate superiority in terms of improved survival, recovery of kidney function, metabolic and clinical outcomes among modes of dialysis for people with AKI (Gabriel 2007b; Gabriel 2008; George 2011; Ponce 2011).

Dialysis types vary significantly and their use may be influenced by the treatment setting. Although both extracorporeal therapy and PD are provided for people with AKI, PD is seldom used in developed countries because of efficacy concerns (Hyman 2002). However, in resource-limited settings PD is favoured as a low cost and widely available dialysis option (Mohandas 2004; Sharma 2003). Moreover, PD has been shown to be effective in patients in hypercatabolic state (Gabriel 2008) and those with acidosis (Dell'Aquila 2006).

\section{How the intervention might work}

$\mathrm{PD}$, which uses the peritoneum as a dialysis membrane by means of dispersion and ultrafiltration, is aimed to remove urinary toxins, excess fluid and correct electrolyte and acid-base balance disorders. Improvements in PD have increased fluid removal efficacy and metabolic control in people with AKI (Chitalia 2002; Gabriel 2006; Gabriel 2007b).

\section{Why it is important to do this review}

Recent studies have shown that PD may be a costeffective alternative to extracorporeal therapy in resource-limited healthcare settings. Furthermore, similar rates of mortality and recovery of kidney function in AKI patients have been reported between PD and extracorporeal therapy (Gabriel 2008;
George 2011). Thus, we will seek to systematically review the current literature and to analyse all studies comparing PD with extracorporeal therapy or different PD modalities for the treatment of AKI.

\section{O B J E C T IVES}

The aim of this review was to evaluate the benefits and harms of PD for patients with AKI compared with extracorporeal therapy or different PD modalities.

\section{METHODS}

\section{Criteria for considering studies for this review}

\section{Types of studies}

All RCTs and quasi-RCTs (RCTs in which allocation to treatment will be obtained by alternation, use of alternate medical records, date of birth or other predictable methods) looking at the benefits and harms of PD comparing with extracorporeal therapy or different PD modalities for AKI were considered eligible for inclusion, whether or not mortality rate and kidney function recovery were set as the primary outcome. Cross-over studies were excluded.

\section{Types of participants}

\section{Inclusion criteria}

We included patients with AKI who were randomised to receive PD or extracorporeal therapy, regardless of their age, sex, primary disease and clinical course.

\section{Exclusion criteria}

1. Patients who had previously received any mode of dialysis during the current illness, and who had pre-renal AKI, urinary tract obstruction, rapidly progressive glomerulonephritis, a history of chronic kidney insufficiency, kidney transplant.

2. Patients receiving both PD and extracorporeal therapy.

\section{Types of interventions}

1. PD (including all different modalities) plus supportive treatment versus extracorporeal therapy (including all different modalities of IHD or CRRT) plus supportive treatment.

2. PD (including all different modalities) versus extracorporeal therapy (including all different modalities of IHD or CRRT)

3. Comparison of different modalities of PD.

Supportive treatment might include approaches to treat underlying kidney or other diseases and to improve disorders that were linked to AKI, such as sepsis, malaria, and acute tubular necrosis. Supportive treatment should be comparable between PD and extracorporeal therapy.

\section{Types of outcome measures}

All the outcomes were assessed at fixed time points (e.g. 30 days, 90 days, the end of follow-up, at ICU discharge or hospital discharge).

\section{Primary outcomes}

All-cause mortality (death from any cause at the end of follow-up). 


\section{Secondary outcomes}

1. Recovery of kidney function (kidney function recovery is defined as no need of dialysis with improvement of urine output and a progressive fall in serum creatinine ( $\mathrm{SCr}$ ))

2. Laboratory index (e.g. SCr, Kt/V, weekly endogenous creatinine clearance $(\mathrm{CrCl})$, serum potassium, serum phosphorus)

3. Economic cost (total cost of dialysis and hospitalisation)

4. Metabolic and acid-base control ( $\mathrm{pH}$ and bicarbonate)

5. Fluid removal

6. Length of in-hospital and ICU stays

7. Duration of dialysis (days)

8. Adverse events (including bleeding, peritonitis, respiratory Insufficiency, hypoalbuminaemia, infection)

9. Blood pressure during dialysis $(\mathrm{mm} \mathrm{Hg})$

10.Vasopressor support

\section{Search methods for identification of studies}

\section{Electronic searches}

We searched the Cochrane Kidney and Transplant Register of Studies up to 29 May 2017 through contact with the Information Specialist using search terms relevant to this review. The Register contains studies identified from the following sources.

1. Monthly searches of the Cochrane Central Register of Controlled Trials (CENTRAL).

2. Weekly searches of MEDLINE OVID SP.

3. Handsearching of kidney and transplant-related journals and the proceedings of major kidney and transplant conferences.

4. Searching of the current year of EMBASE OVID SP.

5. Weekly current awareness alerts for selected kidney and transplant journals.

6. Searches of the International Clinical Trials Register (ICTRP) Search Portal and ClinicalTrials.gov.

Studies contained in the Register are identified through search strategies for CENTRAL, MEDLINE, and EMBASE based on the scope of Cochrane Kidney and Transplant. Details of these strategies, as well as a list of handsearched journals, conference proceedings and current awareness alerts, are available in the "Specialised Register" section of information about Cochrane Kidney and Transplant.

See Appendix 1 for search terms used in strategies for this review.

\section{Searching other resources}

1. Reference lists of review articles, relevant studies and clinical practice guidelines.

2. Letters seeking information about unpublished or incomplete studies to investigators known to be involved in previous studies.

3. The China Biological Medicine Database (CBM-disc from 1979), a database of Chinese biomedical research literature.

\section{Data collection and analysis}

\section{Selection of studies}

The search strategy described was used to obtain titles and abstracts of studies that might be relevant to the review. The titles and abstracts were screened independently by two authors, who discarded studies that were not applicable; however studies and reviews that might include relevant data or information on studies will be retained initially. Two authors will independently assess retrieved abstracts, and if necessary the full text of these studies, to determine which studies satisfy the inclusion criteria.

\section{Data extraction and management}

Data extraction will be carried out independently by two authors using standard data extraction forms. Studies reported in nonEnglish and non-Chinese language journals were translated before assessment. Where more than one publication of one study exists, reports were grouped together and the report with the most complete data was used in the analyses. Where relevant outcomes were only published in earlier versions, these data were used. Any discrepancy between published versions was to be highlighted. Disagreements were resolved in consultation among all authors.

\section{Assessment of risk of bias in included studies}

The following items were independently assessed by two authors using the risk of bias assessment tool (Higgins 2011) (see Appendix 2).

- Was there adequate sequence generation (selection bias)?

- Was allocation adequately concealed (selection bias)?

- Was knowledge of the allocated interventions adequately prevented during the study?

- Participants and personnel (performance bias)

- Outcome assessors (detection bias)

- Were incomplete outcome data adequately addressed (attrition bias)?

- Are reports of the study free of suggestion of selective outcome reporting (reporting bias)?

- Was the study apparently free of other problems that could put it at a risk of bias?

\section{Measures of treatment effect}

For dichotomous outcomes (e.g. all-cause mortality, patient survival, recovery of kidney function) results were expressed as risk ratio (RR) with $95 \%$ confidence intervals $(\mathrm{Cl})$. Where continuous scales of measurement were used to assess the effects of treatment (e.g. laboratory index, cost, RRT time, vascular booster dose, quality of life), the mean difference (MD) was used, or the standardised mean difference (SMD) if different scales have been used.

\section{Unit of analysis issues}

Special issues in the analysis of studies with non-standard designs, such as cluster-RCTs, were to be described.

\section{Dealing with missing data}

Any further information required from the original author was requested by written correspondence (e.g. emailing to corresponding author) and any relevant information obtained in this manner was included in the review. Evaluation of important numerical data such as screened, randomised patients as well as intention-to-treat, as-treated and per-protocol population were carefully performed. Attrition rates, for example drop-outs, losses to follow-up and withdrawals were investigated. Issues 
of missing data and imputation methods (e.g. last-observationcarried-forward) were critically appraised (Higgins 2011).

\section{Assessment of heterogeneity}

We first assessed the heterogeneity by visual inspection of the forest plot. Heterogeneity was then analysed using a Chi ${ }^{2}$ test on $\mathrm{N}-1$ degrees of freedom, with an alpha of 0.05 used for statistical significance and with the 12 test (Higgins 2003). A guide to the interpretation of $\mathrm{I}^{2}$ values is as follows.

- $0 \%$ to $40 \%$ : might not be important

- $30 \%$ to $60 \%$ : may represent moderate heterogeneity

- $50 \%$ to $90 \%$ : may represent substantial heterogeneity

- $75 \%$ to $100 \%$ : considerable heterogeneity.

\section{Assessment of reporting biases}

Funnel plots were to be used to assess for the potential existence of small study bias (Higgins 2011). There were insufficient studies to do this.

\section{Data synthesis}

Data were pooled using the random-effects model but the fixedeffect model was be used to ensure robustness of the model chosen and susceptibility to outliers.

\section{Subgroup analysis and investigation of heterogeneity}

We performed subgroup analysis to identify possible sources of heterogeneity. Differences in participant sources (ethnicity, age and underlying kidney diseases) and disparities related to intervention (different dialytic modalities, PD and HD dose and mode) might be attributed to heterogeneity. The following subgroup analyses were planned to investigate any observed heterogeneity.

1. Primary diseases

2. Disease severity

3. Extracorporeal therapy modes

4. Timing of treatment commencement.

Adverse effects were tabulated and assessed with descriptive techniques because they were likely to be different for the various agents used. Where possible, the risk difference (RD) with $95 \%$ $\mathrm{Cl}$ was calculated for each adverse effect, either compared to no treatment or to another agent.

\section{Sensitivity analysis}

Where possible, we performed sensitivity analyses to evaluate the effect on the overall result of removing studies with low methodological quality. Studies with inadequate allocation concealment; achieving inadequate follow-up and unblinded outcome assessment, or blinding of outcome assessment uncertain, were considered as being of low methodological quality. We performed sensitivity analyses to explore the influence of the following factors on effect size.

- Repeating the analysis excluding unpublished studies.

- Repeating the analysis taking account of risk of bias.

- Repeating the analysis excluding any very long or large studies to establish how much they dominate the results.

- Repeating the analysis excluding studies using the following filters: diagnostic criteria, language of publication, source of funding (industry versus other), and country.

\section{'Summary of findings' tables}

We presented the main results of the review in 'Summary of findings' tables. These tables present key information concerning the quality of the evidence, the magnitude of the effects of the interventions examined, and the sum of the available data for the main outcomes (Schünemann 2011a). The 'Summary of findings' tables also include an overall grading of the evidence related to each of the main outcomes using the GRADE (Grades of Recommendation, Assessment, Development and Evaluation) approach (GRADE 2008). The GRADE approach defines the quality of a body of evidence as the extent to which one can be confident that an estimate of effect or association is close to the true quantity of specific interest. The quality of a body of evidence involves consideration of within-trial risk of bias (methodological quality), directness of evidence, heterogeneity, precision of effect estimates and risk of publication bias (Schünemann 2011b). We presented the following outcomes in the 'Summary of findings' tables.
1. All-cause mortality
2. Recovery of kidney function
3. Duration of dialysis (hours)
4. Delivered Kt/V
5. Correction of acidosis
6. Fluid removal (L/d)
7. Infectious complications

\section{RES U LTS}

\section{Description of studies}

\section{Results of the search}

After searching the Register of Studies and the China Biological Medicine Database we identified 968 records. After duplicates were removed and titles and abstracts screened we retrieved 21 full-text articles for further assessment. Of these, six studies (15 records) were included and five studies (six records) were excluded (Figure $1)$. 
Figure 1. Flow chart of the article selection process

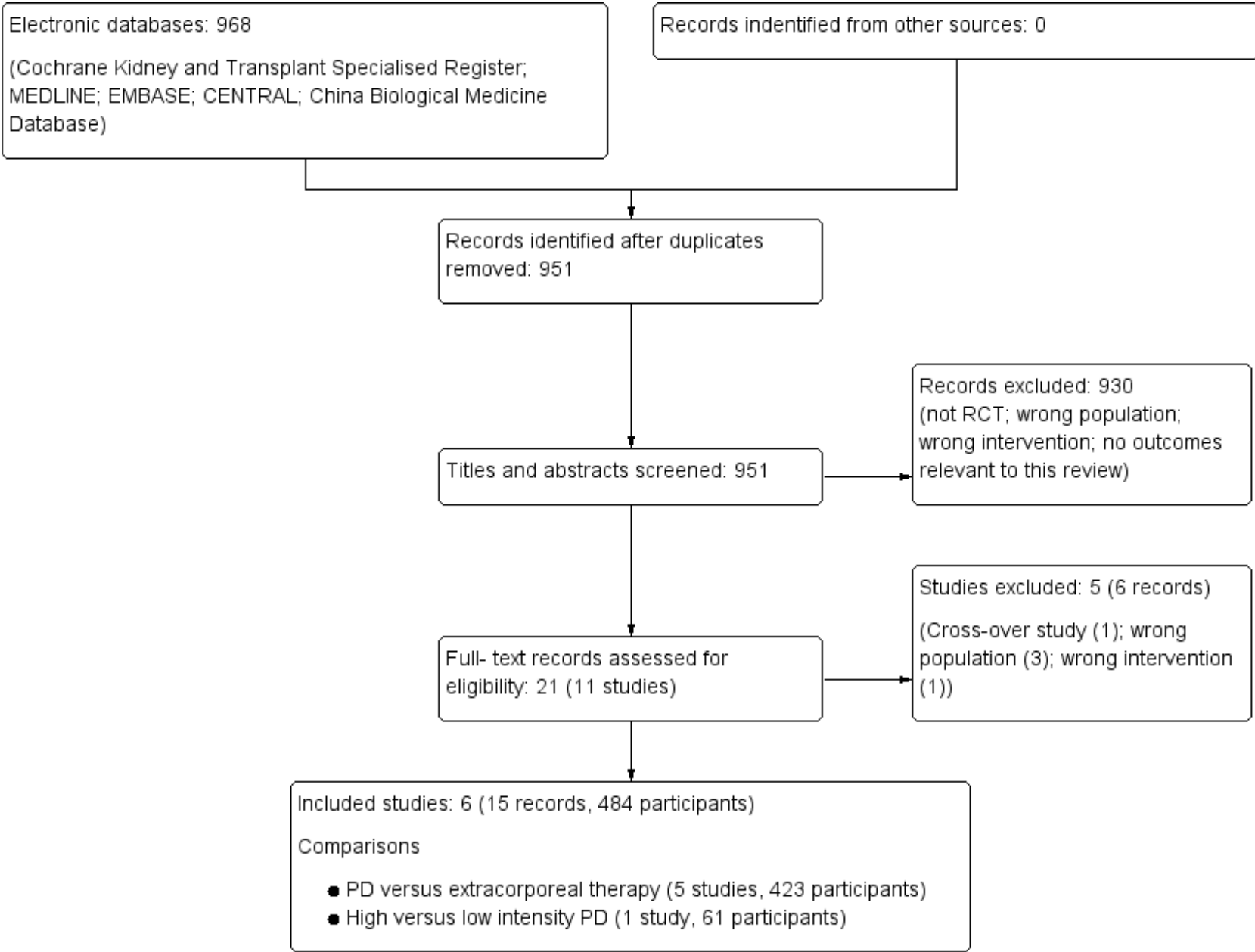

\section{Included studies}

Six studies (Alhwiesh 2014; Gabriel 2008; George 2011; Phu 2002; Ponce 2011; Ponce 2013) enrolling 484 participants were included. Three studies focused on AKI patients with critical illness (Alhwiesh 2014; Phu 2002; George 2011), two studies on general AKI patients (Gabriel 2008; Ponce 2011), and one study enrolled any patient with AKI (Ponce 2013). Three studies were from Brazil (Gabriel 2008; Ponce 2011; Ponce 2013), one from India (George 2011), one from Saudi Arabia (Alhwiesh 2014), and one from Vietnam (Phu 2002). The characteristics of studies fulfilling the inclusion criteria are listed in Characteristics of included studies. In total, 233 patients underwent PD and 251 patients underwent extracorporeal therapy.

High volume PD (HVPD) was performed in all included studies as the modality of PD. One study (Ponce 2011) focused on high versus low intensity of $P D$, and the other studies compared PD with daily haemodialysis (DHD) (Gabriel 2008); extended daily haemodialysis (EDD) (Ponce 2013), or CRRT (Alhwiesh 2014; George 2011; Phu 2002).

Five studies reported all-cause mortality (Gabriel 2008; George 2011; Phu 2002; Ponce 2011; Ponce 2013), four reported recovery of kidney function (Gabriel 2008; Phu 2002; Ponce 2011; Ponce 2013), two reported duration of dialysis (hours) (Gabriel 2008; George 2011), three reported delivered weekly Kt/V (Gabriel 2008; Ponce 2011; Ponce 2013), two reported the correction of acidosis (George 2011; Phu 2002), four reported fluid removal (L/d) (Gabriel 2008; George 2011; Ponce 2011; Ponce 2013); and three reported infection (Gabriel 2008; Ponce 2011; Ponce 2013).

\section{Excluded studies}

We excluded five studies. Three studies enrolled both AKI and CKD patients and data could not be separated (Arogundade 2005; Kalra 1989; Nand 1996), one study compared PD + verapamil to HD, however verapamil was not used in the HD group (Nand 1997a), and one study was a cross-over study (Chitalia 2002).

\section{Risk of bias in included studies}

Details of the assessment of risk of bias of included studies are presented in Figure 2 and Figure 3. One study, available only as an abstract, reported limited information and we were unable to complete a risk of bias assessment (Alhwiesh 2014). 
Figure 2. Risk of bias graph: review authors' judgements about each risk of bias item presented as percentages across all included studies.

Random sequence generation (selection bias)

Allocation concealment (selection bias)

Blinding of participants and personnel (performance bias)

Blinding of outcome assessment (detection bias)

Incomplete outcome data (attrition bias)

Selective reporting (reporting bias)

Other bias
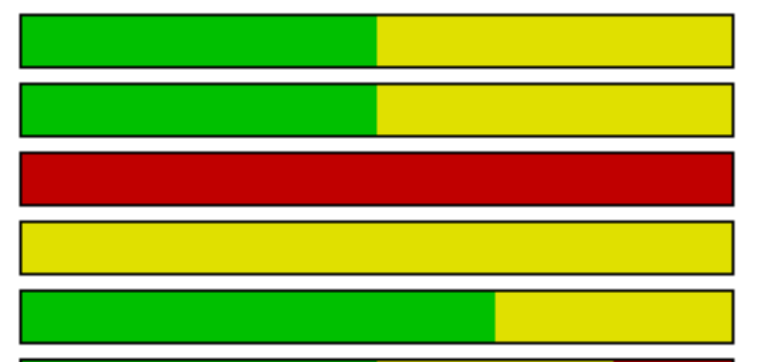

L

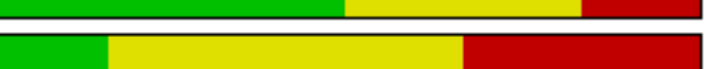

\begin{tabular}{|lllll}
\hline 1 & & 1 & & \\
\hline $0 \%$ & $25 \%$ & $50 \%$ & $75 \%$ & $100 \%$
\end{tabular}


Figure 3. Risk of bias summary: review authors' judgements about each risk of bias item for each included study.

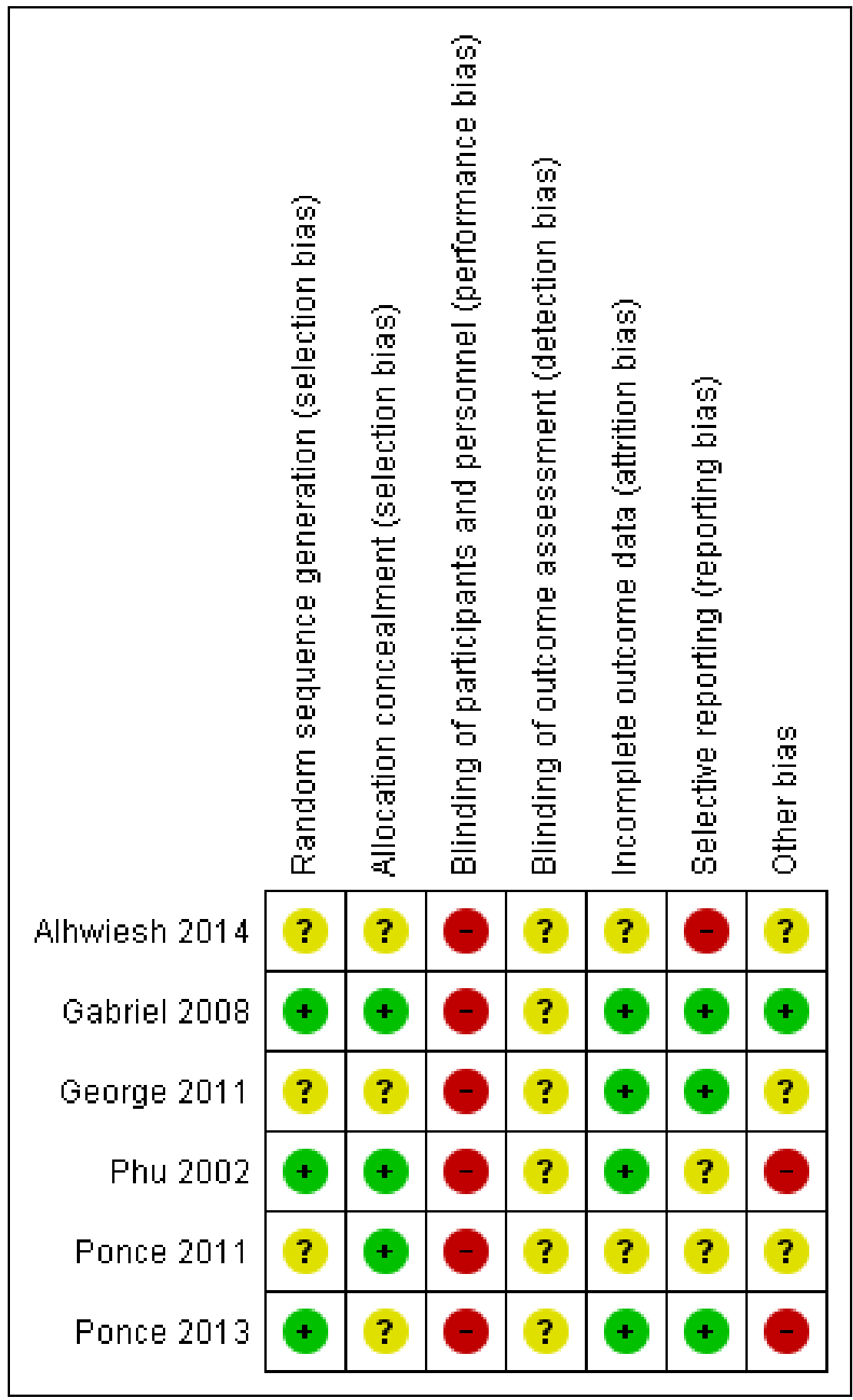

\section{Allocation}

\section{Random sequence generation}

Random sequence generation was judged to be at low risk of bias in three studies (Gabriel 2008; Phu 2002; Ponce 2013) and unclear in three studies (Alhwiesh 2014; George 2011; Ponce 2011).

\section{Allocation concealment}

Allocation concealment was judged to be at low risk of bias in three studies (Gabriel 2008; Phu 2002; Ponce 2011) and unclear in three studies (Alhwiesh 2014; George 2011; Ponce 2013).

\section{Blinding}

Performance bias was high in all studies and detection bias was unclear. 


\section{Incomplete outcome data}

Attrition bias was judged to be low in four studies (Gabriel 2008; George 2011; Phu 2002; Ponce 2013) and unclear in two studies (Alhwiesh 2014; Ponce 2011).

\section{Selective reporting}

Reporting bias was judged to be high in one study (Alhwiesh 2014), low in three studies (Gabriel 2008; George 2011; Ponce 2013), and unclear in two studies (Phu 2002; Ponce 2011).

\section{Other potential sources of bias}

One study was stopped in advance, as only 50 patients were recruited over 3 years (George 2011). One study was stopped because of obvious differences in mortality (Phu 2002). In Ponce 2013, despite randomisation, there were significant differences between PD and extracorporeal therapy in some baseline characteristics, including pre-dialysis BUN, and creatinine levels.

\section{Effects of interventions}

See: Summary of findings for the main comparison Peritoneal dialysis compared with haemodialysis for acute kidney injury

\section{All-cause mortality}

PD compared to extracorporeal therapy probably makes little or no difference to all-cause mortality (Analysis 1.1 (4 studies, 383 participants): RR $1.12,95 \% \mathrm{Cl} 0.81$ to $1.55 ; 1^{2}=69 \%$; moderate certainty evidence). In Phu 2002, a total of 108 patients with AKI requiring dialysis were planned to be recruited. When 70 patients were enrolled, it showed an unexpected higher mortality rate in the PD group, so the study was stopped. AKI was mainly caused by falciparum malaria in this study, while in the other three studies AKI was mainly caused by sepsis or haemodynamic disturbances. When this study was removed from the analysis 12 was $0 \%$ with no change to the significance of the result (RR $1.00,95 \% \mathrm{Cl} 0.85$ to 1.17 ).

Ponce 2011 reported high versus low intensity PD probably makes little or no difference to all-cause mortality (Analysis 2.1 (1 study, 61 participants): RR $1.03,95 \% \mathrm{Cl} 0.65$ to 1.63 ).

\section{Recovery of kidney function}

PD compared to extracorporeal therapy probably makes little or no difference to kidney function recovery (Analysis 1.2 (3 studies, 333 participants): RR $0.95,95 \% \mathrm{Cl} 0.68$ to $1.35 ; \mathrm{I}^{2}=0 \%$; moderate certainty evidence).

Ponce 2011 reported high versus low intensity PD probably makes little or no difference to kidney function recovery (Analysis 2.2 (1 study, 61 participants): RR $1.00,95 \% \mathrm{Cl} 0.74$ to 1.35 ).

\section{Weekly delivered Kt/V}

It is uncertain whether the weekly delivered $\mathrm{Kt} / \mathrm{V}$ is lower with PD compared to extracorporeal therapy (Analysis 1.3 (2 studies, 263 participants): MD $-2.47,95 \% \mathrm{Cl}-5.17$ to $0.22 ; 1^{2}=99 \%$; very low certainty evidence). Heterogeneity was high and this may be due to the different extracorporeal therapies used in the two studies (Gabriel 2008; Ponce 2013).
Ponce 2011 reported lower weekly delivered Kt/V with low intensity PD compared to high intensity PD (Analysis 2.3 (1 study, 61 participants): $\mathrm{MD} 1.13,95 \% \mathrm{Cl} 0.91$ to 1.35$)$.

\section{Correction of acidosis}

It is uncertain whether PD compared to extracorporeal therapy corrected acidosis (Analysis 1.4 (2 studies, 89 participants): RR $1.32,95 \% \mathrm{Cl} 0.13$ to $13.60 ; \mathrm{I}^{2}=96 \%$; very low certainty evidence). Heterogeneity was high and this may be due to the different extracorporeal therapies used in the two studies (George 2011; Phu 2002).

Correction of acidosis was not reported for high versus low intensity PD.

\section{Fluid removal}

PD probably slightly reduces the amount of fluid removal compared to extracorporeal therapy (Analysis 1.5 (3 studies, 313 participants): MD $-0.59 \mathrm{~L} / \mathrm{d}, 95 \% \mathrm{Cl}-1.19$ to $0.01 ; \mathrm{I}^{2}=89 \%$; low certainty evidence). Heterogeneity was high and this may be due to the different extracorporeal therapies used in the three studies (Gabriel 2008; George 2011; Ponce 2013).

Ponce 2011 reported less fluid removal with low intensity PD (Analysis 2.4 ( 1 study, 61 participants): MD $0.30 \mathrm{~L} / \mathrm{d}, 95 \% \mathrm{Cl}-0.03$ to 0.63).

\section{Duration of dialysis}

It is uncertain whether the duration of dialysis is reduced with PD compared to extracorporeal therapy (Analysis 1.6 (2 studies, 170 participants): $\mathrm{MD}-1.01$ hours, $95 \% \mathrm{Cl}-91.49$ to $89.47 ; \mathrm{I}^{2}=98 \%$; very low certainty evidence). Heterogeneity was high and this may be due to the different extracorporeal therapies used in the two studies (Gabriel 2008; George 2011).

Duration of dialysis was not reported for high versus low intensity PD.

\section{Adverse effects - infection}

PD probably made little or no difference to infectious complications compared to extracorporeal therapy (Analysis 1.7 (2 studies, 263 participants): RR $1.03,95 \% \mathrm{Cl} 0.60$ to $1.78 ; \mathrm{I}^{2}=0 \%$; low certainty evidence).

Ponce 2011 reported little or no difference to the risk of infection between high and low intensity PD (Analysis 2.5 (1 study, 61 participants): RR $0.97,95 \% \mathrm{Cl} 0.27$ to 3.52 ).

\section{Other outcomes}

Gabriel 2008 reported that the HVPD and DHD were similar in metabolic control. $\mathrm{SCr}$ was stabilized after the same number of dialysis sessions. Mean SCr levels after four sessions of HVPD and DHD were $4.6 \pm 1.0$ and $5.5 \pm 1.3 \mathrm{mg} / 100 \mathrm{~mL}$ respectively.

Phu 2002 and George 2011 compared the economic cost of dialysis. Phu 2002 observed the mean cost of the hospital stay (from the diagnosis of AKI to discharge) for patients assigned to PD was $\$ 1,580$ (95\% Cl $\$ 1,170$ to $\$ 2,000)$, as compared with $\$ 1,150$ (95\% Cl $\$ 960$ to $\$ 1,330$ ) for patients assigned to CRRT. The mean costs per survivor were $\$ 3,000(95 \% \mathrm{Cl} \$ 2,210$ to $\$ 3,790)$ for PD and $\$ 1,340$ $(95 \% \mathrm{Cl} \$ 1,130$ to $\$ 1,560)$ for haemofiltration. However, George 
2011 observed that cost of disposables was higher in continuous venovenous haemodiafiltration (CVVHDF,) than in HVPD (INR 7184 \pm 1436 versus INR $3009 \pm 1643, \mathrm{P}<0.001$ )

Length of in-hospital and ICU stays, blood pressure during dialysis ( $\mathrm{mm} \mathrm{Hg}$ ), and vasopressor support were not reported in any of the included studies.

\section{DISCUSSION}

\section{Summary of main results}

A total of six studies (484 participants) where included in our review. Five studies compared HVPD with DHD (Gabriel 2008), extended DHD (Ponce 2013), or CRRT (Alhwiesh 2014; George 2011; Phu 2002). One study focused on the intensity of PD (Ponce 2011). Overall, this systematic review represents a total of 484 patients. All of the studies came from low to middle income countries; there were no data available from high income countries. Overall there was little or no difference between PD and extracorporeal therapy on allcause mortality, recovery of kidney function recovery, duration of dialysis, correction of acidosis, and infectious complications. Fluid removal (L/d) was probably lower with PD and weekly delivered Kt/ $\checkmark$ might be higher with extracorporeal therapy. There was little or no difference between high and low intensity of PD for mortality or kidney function recovery.

\section{Overall completeness and applicability of evidence}

Although the effect of PD on AKI in high income countries may be unclear (Hyman 2002), PD is often used in low-resource countries because of low cost, availability, and ease of administration (Phu 2002; Mohandas 2004; Sharma 2003). This finding may be considered surprising, because PD has been considered as a better dialysis modality that preserving renal haemodynamics and residual kidney function, as no extracorporeal circulation is required, which could theoretically result in better outcomes. The finding is in agreement with our included studies which all come from low-resource countries, such as Brazil, Vietnam, and India. The reason for choice of PD is likely multifactorial; one reason is personal tendency of nephrologist, another important reason is different aetiology (Cerda 2008). In high income countries, patients with AKI often accompany with multiorgan failure and multiple comorbidities in elderly patients particular particularly in ICU. However, in low-resource countries, AKI happens more often in young and previously healthy individuals, most of the patients have a single disease or condition, such as infection or toxins. These factors may affect the choice of dialysis modality.

\section{Quality of the evidence}

Only five studies provided data that could be potentially metaanalysed, and there were several limitations of the quantity of evidence. First, it must be noted that half studies were small (fewer than 100 patients). Second, not all included studies reported all primary outcomes. For instance, $75 \%$ reported recovery of kidney function and fluid removal, 50\% reported duration of dialysis, delivered weekly $\mathrm{Kt} / \mathrm{V}$, correction of acidosis and infection rate. Thus, there might be outcome reporting bias.

The high mortality rate among patients with AKI especially in intensive care units remains an unsolved problem in spite of the technological advances in RRT (Himmelfarb 2007; Ricci 2006; Uchino 2005). It has been reported that the mortality of patients with AKI has been estimated at $23.9 \%$ in adults and $13.8 \%$ in children (Susantitaphong 2013). There is no consensus in the literature on the best dialysis modality in patients with AKI; both PD and extracorporeal therapy are the possible options for the treatment of AKI. Phu 2002 reported that mortality with PD was threefold higher than mortality with HF; however, most of other studies didn't see a similar effect. The authors used intermittent PD with rigid catheters, an open system, manual exchanges, and a too-short dwell time, which may contribute to the poor outcome. In addition, severe acidosis secondary to the combination of severe sepsis or malaria was a major contributor to the high mortality. Our review demonstrated that pooled mortality of dialysis patients was $58.2 \%$ for PD and $56.2 \%$ for extracorporeal therapy. Metaanalysis suggested that all-cause mortality was similar in both groups. This finding is consistent with the review of Chionh 2013, which suggested that no significant differences was observe in mortality between PD and extracorporeal therapy in patients with AKI, however most data was from the cohort studies. Our mortality data appeared equivalent with other centres in India, with a mortality of $60 \%$ observed in septic patients (Chatterjee 2009). It is speculated that the main reason influencing mortality was the severity of disease and the need for ventilator support, but not the modality of dialysis (George 2011). However, because of limited number of patients and RCTs, this finding should be interpreted with caution until more studies are available.

Three studies assessed the difference in recovery of kidney function between PD and extracorporeal therapy. Only one study identified that the recovery of kidney function of haemofiltration was superior to PD. Technical problems, severe primary infections and acidosis caused by infection may contribute to the poor outcome (Phu 2002). Meta-analysis suggested that recovery of kidney function was similar in both groups. However, there were differences in the speed of kidney function recovery. One study suggested that the recovery of kidney function in patients treated with HF required for a significantly shorter period compared with PD (Phu 2002). However, Gabriel 2008 and Mehta 2007 both reported that $\mathrm{PD}$ was associated with a significantly faster recovery of kidney function.

In terms of other secondary outcomes, no differences were identified in duration of dialysis (hours), correction of acidosis, and fluid removal $(\mathrm{L} / \mathrm{d})$ between $\mathrm{PD}$ and extracorporeal therapy. Whereas, delivered $\mathrm{Kt} / \mathrm{V}$ was higher in HD group. Most of the published studies had conflicting results. There are several factors that impact the outcome of PD, such as dialysate dose, dwell times, membrane permeability and area (Ronco 2006). Longer dwell times which may be conducive to fluid removal may reduce the urea and creatinine clearance (Jeloka 2006). A recent study had suggested that dialysis dose may be a major factor influencing the outcome of AKI treatment (Schiffl 2002). The reporting of these factors was either absent or different among the four included studies, making it difficult to draw a specific relationship between these factors and clinical outcomes. Further clinical subgroup analyses were not performed.

The most common complications related to PD and extracorporeal therapy are peritonitis, catheter infection, catheter leakage, catheter obstruction and migration. Two studies reported peritonitis related to PD and catheter infection related to extracorporeal therapy; infectious complications related to dialysis method were similar in both studies (Gabriel 2008; Ponce 2013). 
Peritonitis incidence was similar to previous studies in the literature (Gabriel 2006). The included studies didn't report length of inhospital or ICU stays, blood pressure during dialysis $(\mathrm{mm} \mathrm{Hg})$, or vasopressor support which might influence outcomes in AKI, leading to the lack of further analysis according to design in advance.

\section{Potential biases in the review process}

Both low quantity and quality of available evidence has meant that any differences between the two groups remain extremely uncertain. Some limitations of our study should be pointed out. First, only four studies were included in our meta-analysis, eligible studies comparing specific outcomes were extremely limited. The limited sample size made it difficult to observe a clinically significant difference in outcomes. We therefore did not perform further subgroup analyses based on indicators such as modality of PD and extracorporeal therapy, differences of dialysis dose, primary diseases, disease severity, and timing of treatment commencement, which may have added to heterogeneity. Second, although we extracted data at the end of studies, the duration of each study varied. Some studies were terminated in advance, which possibly have added to generation of bias. Third, all studies in our review were performed in low to middle income countries. Four, unreported outcomes of interest in some studies possibly lead to reporting bias. Last, there was no enough data to evaluate the length of stays in the ICU, intradialytic BP and vasopressor requirements in our review, which might have significant impact in AKI outcomes. Regardless of these limitations, we have decreased bias throughout the methods of research identification, data selection, and statistical analysis. These steps should enhance accuracy of our review.

\section{Agreements and disagreements with other studies or reviews}

Chionh 2013 included 11 studies to evaluate the effect of PD on AKI patients in comparison with extracorporeal therapy, and reported no difference in mortality. In subgroup analyses, mortality was similar in observational studies (OR $0.96,95 \% \mathrm{Cl}, 0.53$ to 1.71 ) and RCTs (OR 1.50, 95\% Cl, 0.46 to 4.86). However, only three of our included studies (Gabriel 2008; George 2011; Phu 2002) were pooled in the meta-analysis of mortality. We included four RCTs (Gabriel 2008; George 2011; Phu 2002; Ponce 2013), and also found no difference in mortality. There was no RCT focusing on PD for paediatric AKI patients, but a recent observational study (Basu 2016) showed that continuous PD was associated with lower mortality compared with daily HD in paediatric AKI patients. The recent International Society for Peritoneal Dialysis guidelines (Cullis 2014) on PD for AKI also suggested that PD should be considered as a suitable method of CRRT in patients with AKI both in high and low resource countries, and PD was also a safe and effective method of blood purification and fluid removal for paediatric AKI patients.

\section{AUTHORS' CONCLUSIONS}

\section{Implications for practice}

Based on moderate (mortality, recovery of kidney function), low (infectious complications), or very low certainty evidence (correction of acidosis) there is probably little or no difference between PD and extracorporeal therapy for treating AKI. Fluid removal (low certainty) and weekly delivered Kt/V (very low certainty) may be higher with extracorporeal therapy. Due to the lack of sufficient good-quality clinical data, choice of dialysis modality should be made according to the patient's clinical symptoms, laboratory examination indexes and local resources.

\section{Implications for research}

There is currently insufficient evidence to indicate any difference in all-cause mortality or kidney function recovery between PD and extracorporeal therapy for treating AKI. HVPD may be an effective modality for the treatment of patients with AKI however more largesample, high-quality RCTs are required to give a solid conclusion in this area. In addition, more RCTs related to dialysis modality, dose, flow, and dwell time of PD compared with different modalities of extracorporeal therapy should be performed.

\section{ACKN OWLEDGEMENTS}

The authors would like to thank the referees and Cochrane Kidney and Transplant's editorial team for their comments and feedback during the preparation of this review. 


\section{R E F E R E N C E S}

\section{References to studies included in this review}

Alhwiesh 2014 \{published data only\}

Alhwiesh A, Nasreldin MA, Saeed I. Comparing tidal peritoneal dialysis to CRRT in critically ill patients with acute kidney injury. A single centre experience [abstract no: SP461]. Nephrology Dialysis Transplantation 2014;29(Suppl 3):iii226. [EMBASE: 71492088]

Gabriel 2008 \{published data only (unpublished sought but not used)\}

* Gabriel DP, Caramori JT, Martim LC, Barretti P, Balbi AL. High volume peritoneal dialysis vs daily hemodialysis: a randomized, controlled trial in patients with acute kidney injury. Kidney International - Supplement 2008, (108):S87-93. [MEDLINE: 18379555]

Gabriel DP, Caramori JT, Martin LC, Barretti P, Balbi AL. Continuous peritoneal dialysis compared with daily hemodialysis in patients with acute kidney injury. Peritoneal Dialysis International 2009;29 Suppl 2:S62-71. [MEDLINE: 19270234]

\section{George 2011 \{published data only (unpublished sought but not used)\}}

George J, Pisharody R, Upendran B, Varma S, Leelakumari M, Palliyil S. Clinical trial of continuous veno venous hemodiafiltration and peritoneal dialysis in critically ill acute renal failure [abstract no: SaP218]. Nephrology Dialysis Transplantation 2007;22(Suppl 6):vi305.

* George J, Varma S, Kumar S, Thomas J, Gopi S, Pisharody R. Comparing continuous venovenous hemodiafiltration and peritoneal dialysis in critically ill patients with acute kidney injury: a pilot study. Peritoneal Dialysis International 2011;31(4):422-9. [MEDLINE: 21357934]

Phu 2002 \{published data only (unpublished sought but not used)\} Bazari $\mathrm{H}$. Hemofiltration and peritoneal dialysis in infectionassociated acute renal failure. New England Journal of Medicine 2003;348(9):858-60. [MEDLINE: 12608400]

Casserly LF. Hemofiltration and peritoneal dialysis in infectionassociated acute renal failure. New England Journal of Medicine 2003;348(9):858-60. [MEDLINE: 12608398]

Daugirdas JT. Peritoneal dialysis in acute renal failure--why the bad outcome?. New England Journal of Medicine 2002; Vol. 347, issue 12:933-5. [MEDLINE: 12239265]

Fruchter $\mathrm{O}$. Hemofiltration and peritoneal dialysis in infectionassociated acute renal failure. New England Journal of Medicine 2003;348(9):858-60. [MEDLINE: 12608399]

* Phu NH, Hien TT, Mai NT, Chau TT, Chuong LV, Loc PP, et al. Hemofiltration and peritoneal dialysis in infection-associated acute renal failure in Vietnam. New England Journal of Medicine 2002;347(12):895-902. [MEDLINE: 12239258]
Rao PS, Modi KS. Hemofiltration and peritoneal dialysis in infection-associated acute renal failure. New England Journal of Medicine 2003;348(9):858-60. [MEDLINE: 12606745]

\section{Ponce 2011 \{published data only\}}

Ponce D, Balbi AL. Different prescribed doses of high volume peritoneal dialysis and outcome of patients with acute kidney injury [abstract]. Peritoneal Dialysis International 2012;32(Suppl 3):S4. [EMBASE: 71927756]

Ponce D, Brito GA, Abrao JG, Balb AL. Different prescribed doses of high-volume peritoneal dialysis and outcome of patients with acute kidney injury. Advances in Peritoneal Dialysis 2011;27(1):118-24. [MEDLINE: 22073842]

Ponce 2013 \{published data only (unpublished sought but not used)\}

Ponce D, Balbi AL, Abrao JM, Berbel MN, Pinto MP, Brito GA. High volume peritoneal dialysis (PD) versus sustained low efficiency dialysis: a randomized controlled trial in patients with acute kidney injury: initial results [abstract]. Peritoneal Dialysis International 2012;32:S4. [EMBASE: 71927757]

* Ponce D, Berbel MN, Abrao JM, Goes CR, Balbi AL. A randomized clinical trial of high volume peritoneal dialysis versus extended daily hemodialysis for acute kidney injury patients. International Urology \& Nephrology 2013;45(3):869-78. [MEDLINE: 23065432]

\section{References to studies excluded from this review}

Arogundade 2005 \{published data only\}

Arogundade FA, Ishola DA Jr, Sanusi AA, Akinsola A. An analysis of the effectiveness and benefits of peritoneal dialysis and haemodialysis using Nigerian made PD fluids. African Journal of Medicine \& Medical Sciences 2005;34(3):227-33. [MEDLINE: 16749353]

\section{Chitalia 2002 \{published data only\}}

Chitalia VC, Almeida AF, Rai H, Bapat M, Chitalia KV, Acharya VN, et al. Is peritoneal dialysis adequate for hypercatabolic acute renal failure in developing countries?. Kidney International 2002;61(2):747-57. [MEDLINE: 11849419]

Chitalia VC, Fernandes A, Rai H, Bapat M, Chitalia KV, Acharya VN, et al. Is peritoneal dialysis adequate for hypercatabolic acute renal failure? [abstract]. Journal of the American Society of Nephrology 2001;12(Program \& Abstracts):447A. [CENTRAL: CN-00550689]

\section{Kalra 1989 \{published data only\}}

Kalra OP, Abrol L, Chopra JS, Agarwal SK, Prakash C. Optimal exchange volume and dialysate flow rate in peritoneal dialysis. A clinical study. Journal of the Association of Physicians of India 1989;37(12):762-4. [MEDLINE: 2699986]

Nand 1996 \{published data only\}

Nand N, Mahajan SK, Wig N, Sharma M, Aggarwal HK, Seth RK. Comparison of sodium nitroprusside added peritoneal dialysis 
and standard haemodialysis. Journal of the Association of Physicians of India 1996;44(11):780-3. [MEDLINE: 9251452]

\section{Nand 1997a \{published data only\}}

Nand N, Agarwal HK, Mahajan SK, Thukral S, Sharma M, Kumar P. Evaluation of efficacy of standard haemodialysis and verapamil added peritoneal dialysis. Indian Journal of Medical Sciences 1997;51(3):75-81. [MEDLINE: 9355712]

\section{Additional references}

\section{Basu 2016}

Basu B, Mahapatra TK, Roy B, Schaefer F. Efficacy and outcomes of continuous peritoneal dialysis versus daily intermittent hemodialysis in pediatric acute kidney injury. Pediatric Nephrology 2016;31(10):1681-9. [MEDLINE: 27180178]

\section{Bunchman 1994}

Bunchman TE, Donckerwolke RA. Continuous arterialvenous diahemofiltration and continuous veno-venous diahemofiltration in infants and children. Pediatric Nephrology 1994;8(1):96-102. [MEDLINE: 8142241]

\section{Cerda 2008}

Cerda J, Bagga A, Kher V, Chakravarthi RM. The contrasting characteristics of acute kidney injury in developed and developing countries. Nature Clinical Practice Nephrology 2008;4(3):138-53. [MEDLINE: 18212780]

\section{Chatterjee 2009}

Chatterjee S, Todi S, Sahu S, Bhattacharya M. Epidemiology of severe sepsis in India [abstract]. Critical Care 2009;13(Suppl 1):S141. [EMBASE: 70188340]

\section{Chionh 2013}

Chionh CY, Soni SS, Finkelstein FO, Ronco C, Cruz DN. Use of peritoneal dialysis in AKI: a systematic review. Clinical Journal of The American Society of Nephrology: CJASN 2013;8(10):1649-60. [MEDLINE: 23833316]

\section{Cullis 2014}

Cullis B, Abdelraheem M, Abrahams G, Balbi A, Cruz DN, Frishberg Y, et al. Peritoneal dialysis for acute kidney injury. Peritoneal Dialysis International 2014;34(5):494-517. [MEDLINE: 25074995]

\section{Dell'Aquila 2006}

Dell'Aquila R, Rodighiero MP, Spano E, Feriani M, Ronco C. Acid-base balance in peritoneal dialysis. Journal of Nephrology 2006;19 Suppl 9:S104-7. [MEDLINE: 16736431]

\section{Ellis 1997}

Ellis EN, Pearson D, Belsha CW, Berry PL. Use of pump-assisted hemofiltration in children with acute renal failure. Pediatric Nephrology 1997;11(2):196-200. [MEDLINE: 9090663]

\section{Gabriel 2006}

Gabriel DP, Nascimento GV, Caramori JT, Martim LC, Barretti P, Balbi AL. Peritoneal dialysis in acute renal failure. Renal Failure 2006;28(6):451-6. [MEDLINE: 16928612]

\section{Gabriel 2007a}

Gabriel DP, Nascimento GV, Caramori JT, Martim LC, Barretti P, Balbi AL. High volume peritoneal dialysis for acute renal failure. Peritoneal Dialysis International 2007;27(3):277-82. [MEDLINE: 17468475]

\section{Gabriel 2007b}

Gabriel DP, Fernández-Cean J, Balbi AL. Utilization of peritoneal dialysis in the acute setting. Peritoneal Dialysis International 2007;27(3):328-31. [MEDLINE: 17468486]

\section{GRADE 2008}

Guyatt GH, Oxman AD, Vist GE, Kunz R, Falck-Ytter Y, AlonsoCoello $P$, et al. GRADE: an emerging consensus on rating quality of evidence and strength of recommendations. $B M J$ 2008;336(7650):924-6. [MEDLINE: 18436948]

\section{Higgins 2003}

Higgins JP, Thompson SG, Deeks JJ, Altman DG. Measuring inconsistency in meta-analyses. BMJ 2003;327(7414):557-60. [MEDLINE: 12958120]

\section{Higgins 2011}

Higgins JP, Green S (editors). Cochrane Handbook for Systematic Reviews of Interventions Version 5.1.0 [updated March 2011]. The Cochrane Collaboration, 2011. Available from www.cochrane-handbook.org.

\section{Himmelfarb 2007}

Himmelfarb J, Ikizler TA. Acute kidney injury: changing lexicography, definitions, and epidemiology. Kidney International 2007;71(10):971-6. [MEDLINE: 17396117]

\section{Hoste 2006}

Hoste EA, Clermont G, Kersten A, Venkataraman R, Angus DC, De Bacquer D, et al. RIFLE criteria for acute kidney injury are associated with hospital mortality in critically ill patients: a cohort analysis. Critical Care (London, England) 2006;10(3):R73. [MEDLINE: 16696865]

\section{Hsu 2013}

Hsu RK, McCulloch CE, Dudley RA, Lo LJ, Hsu CY. Temporal changes in incidence of dialysis-requiring AKI. Journal of the American Society of Nephrology 2013;24(1):37-42. [MEDLINE: 23222124]

\section{Hyman 2002}

Hyman A, Mendelssohn DC. Current Canadian approaches to dialysis for acute renal failure in the ICU. American Journal of Nephrology 2002;22(1):29-34. [MEDLINE: 11919400]

\section{Jeloka 2006}

Jeloka TK, Ersoy FF, Yavuz M, Sahu KM, Camsari T, Utas C, et al. What is the optimal dwell time for maximizing ultrafiltration with icodextrin exchange in automated peritoneal dialysis patients?. Peritoneal Dialysis International 2006;26(3):336-40. [MEDLINE: 16722026]

\section{Mehta 2007}

Mehta RL, Kellum JA, Shah SV, Molitoris BA, Ronco C, Warnock DG, et al. Acute Kidney Injury Network: report of an 
initiative to improve outcomes in acute kidney injury. Critical care 2007;11(2):R31. [MEDLINE: 17331245]

\section{Mohandas 2004}

Mohandas N, Chellapandian D. Value of intermittent peritoneal dialysis in rural setup. Indian Journal of Peritoneal Dialysis 2004;6(1):19-20.

\section{Piccinni 2011}

Piccinni P, Cruz DN, Gramaticopolo S, Garzotto F, Dal Santo M, Aneloni $\mathrm{G}$, et al. Prospective multicenter study on epidemiology of acute kidney injury in the ICU: a critical care nephrology Italian collaborative effort (NEFROINT). Minerva Anestesiologica 2011;77(11):1072-83. [MEDLINE: 21597441]

\section{Ponce 2012}

Ponce D, Balbi AL, Amerling R. Advances in peritoneal dialysis in acute kidney injury. Blood Purification 2012;34(2):107-16. [MEDLINE: 23095409]

\section{Ricci 2006}

Ricci Z, Ronco C, D’amico G, De Felice R, Rossi S, Bolgan I, et al. Practice patterns in the management of acute renal failure in the critically ill patient: an international survey. Nephrology Dialysis Transplantation 2006;21(3):690-6. [MEDLINE: 16326743]

\section{Ronco 2006}

Ronco C. Factors affecting hemodialysis and peritoneal dialysis efficiency. Contributions to Nephrology 2006;150:1-12. [MEDLINE: 16720985]

\section{Schiffl 2002}

Schiffl H, Lang SM, Fischer R. Daily hemodialysis and the outcome of acute renal failure. New England Journal of Medicine 2002;346(5):305-10. [MEDLINE: 11821506]

\section{Schünemann 2011a}

Schünemann HJ, Oxman AD, Higgins JP, Vist GE, Glasziou P, Guyatt GH. Chapter 11: Presenting results and 'Summary of findings' tables. In: Higgins JP, Green S (editors). Cochrane

\section{CHARACTERISTICS OF STUDIES}

Characteristics of included studies [ordered by study ID]
Handbook for Systematic Reviews of Interventions Version 5.1.0 [updated March 2011]. The Cochrane Collaboration, 2011. Available from www.cochrane-handbook.org.

\section{Schünemann 2011b}

Schünemann HJ, Oxman AD, Higgins JP, Deeks JJ, Glasziou P, Guyatt GH. Chapter 12: Interpreting results and drawing conclusions. In: Higgins JP, Green S (editors). Cochrane Handbook for Systematic Reviews of Interventions Version 5.1.0 [updated March 2011]. The Cochrane Collaboration, 2011. Available from www.cochrane-handbook.org.

\section{Sharma 2003}

Sharma SK, Manandhar D, Singh J, Chauhan HS, Koirala B, Gautam M, et al. Acute peritoneal dialysis in Eastern Nepal. Peritoneal Dialysis International 2003;23 Suppl 2:S196-9. [MEDLINE: 17986547]

\section{Susantitaphong 2013}

Susantitaphong P, Cruz DN, Cerda J, Abulfaraj M, Alqahtani F, Koulouridis I, et al. World incidence of AKI: a meta-analysis. [Erratum appears in Clin J Am Soc Nephrol. 2014 Jun 6;9(6):1148]. Clinical Journal of The American Society of Nephrology: CJASN 2013;8(9):1482-93. [MEDLINE: 23744003]

\section{Uchino 2005}

Uchino S, Kellum JA, Bellomo R, Doig GS, Morimatsu H, Morgera S, et al. Acute renal failure in critically ill patients: a multinational, multicenter study. The Journal of the American Medical Association 2005;294(7):813-8. [MEDLINE: 16106006]

\section{References to other published versions of this review}

\section{Liu 2015}

Liu L, Zhang L, Liu GJ, Fu P. Peritoneal dialysis for acute kidney injury. Cochrane Database of Systematic Reviews 2015, Issue 2. [DOI: 10.1002/14651858.CD011457]

* Indicates the major publication for the study

\section{Alhwiesh 2014}

\begin{tabular}{ll}
\hline Methods & Study design: parallel RCT \\
& - Study duration: not reported \\
\hline Participants & - Country: Saudion of follow-up: not reported \\
- Setting: single centre \\
- Patients with AKI and multi-organ involvement \\
- Number: treatment group (20); control group (20) \\
- Mean age \pm SD (years): not reported \\
- Mechanical ventilation: not reported \\
- ICU: not reported
\end{tabular}


Alhwiesh 2014 (Continued)

- APACHE II score: not reported

- Pre SCr (mg/dL): not reported

- Pre BUN (mg/dL): not reported

- Exclusion criteria: not reported

Interventions

Treatment group

- TPD: no further information provided

Control group

- CVVHDF: no further information provided

\begin{tabular}{ll}
\hline Outcomes & - Death \\
- Recovery of kidney function \\
- Fluid control
\end{tabular}

Notes $\quad$ - Abstract-only publication

- Funding source: not reported

\section{Risk of bias}

Bias Authors' judgement Support for judgement

Random sequence genera- Unclear risk Study was described as randomised, method of randomisation was not reporttion (selection bias) ed

Allocation concealment $\quad$ Unclear risk Insufficient information to permit judgement
(selection bias)

Blinding of participants $\quad$ High risk $\quad$ Open-label study
and personnel (perfor-
mance bias)

\begin{tabular}{lll}
\hline $\begin{array}{l}\text { Blinding of outcome as- } \\
\text { sessment (detection bias) } \\
\text { All outcomes }\end{array}$ & Unclear risk & Insufficient information to permit judgement \\
\hline $\begin{array}{l}\text { Incomplete outcome data } \\
\text { (attrition bias) } \\
\text { All outcomes }\end{array}$ & Unclear risk & Insufficient information to permit judgement \\
\hline $\begin{array}{l}\text { Selective reporting (re- } \\
\text { porting bias) }\end{array}$ & High risk & Abstract-only publication; data presented cannot be meta-analysed \\
\hline Other bias & Unclear risk & Insufficient information to permit judgement \\
\hline
\end{tabular}

Gabriel 2008

\begin{tabular}{ll}
\hline Methods & Study design: parallel RCT \\
& - Study duration: January 2004 to December 2008 \\
& - Duration of follow-up: 30 days \\
\hline Participants & - Country: Brazil
\end{tabular}


Gabriel 2008 (Continued)

- Setting: single centre

- Patients $\geq 18$ years with severe ATN (rapid rise in $\mathrm{SCr}$ of at least $30 \%$ ) caused by a recent ischaemic or nephrotoxic injury

- Number: treatment group (60); control group (60)

- Mean age \pm SD (years): treatment group $(64.2 \pm 19.8)$; control group $(62.5 \pm 21.2)$

- Sex (M/F): treatment group (43/17); control group (40/20)

- Mechanical ventilation: treatment group (68\%); control group (75\%)

- ICU: treatment group (73.3\%); control group (81.7\%)

- APACHE II score: treatment group $(26.9 \pm 8.9)$; control group $(24.1 \pm 8.2)$

- Pre $\mathrm{SCr}(\mathrm{mg} / \mathrm{dL})$ : treatment group (5.8 \pm 1.9$)$; control group $(5.9 \pm 1.4)$

- Pre BUN (mg/dL): treatment group $(116.4 \pm 33.6)$; control group $(112.6 \pm 36.8)$

- Exclusion criteria: functional azotaemia; urinary tract obstruction; acute interstitial nephritis; rapidly progressive glomerulonephritis; history of chronic renal insufficiency; kidney transplantation; pregnancy; severe hyper-catabolism

Interventions

Treatment group

- HVPD: 24 h dialysis with sessions performed 7 days/wk; 2 L exchanges with 35 to 50 min fluid dwell times (total of 36 to $44 \mathrm{~L} / \mathrm{d}$ and 18 to 22 exchanges/d); flexible catheter

Control group

- DHD: 3 h sessions 6 times/wk; polysulfone haemofilter; double lumen catheter

\begin{tabular}{ll}
\hline Outcomes & - Death \\
& - Recovery of kidney function \\
& - Furation of dialysis \\
- Kt $/ \mathrm{V}$ \\
- Infection
\end{tabular}

\section{Risk of bias}

Bias Authors' judgement Support for judgement

Random sequence genera- Low risk Randomisation was performed using random-number tables
tion (selection bias)

\begin{tabular}{lll}
\hline $\begin{array}{l}\text { Allocation concealment } \\
\text { (selection bias) }\end{array}$ & Low risk & Consecutively numbered sealed envelopes
\end{tabular}

Blinding of participants $\quad$ High risk
and personnel (perfor-
mance bias)
All outcomes

$\begin{array}{lll}\text { Blinding of outcome as- } & \text { Unclear risk } \quad \text { Insufficient information to permit judgement }\end{array}$


Gabriel 2008 (Continued)

Selective reporting (re- Low risk $\quad$ All expected outcomes were reported
porting bias)

Other bias Low risk The study appears to be free of other sources of bias

George 2011

\begin{tabular}{ll}
\hline Methods & Study design: parallel RCT \\
& - Study duration: commenced in June 2005 for a 3-year period \\
- Duration of follow-up: not reported
\end{tabular}

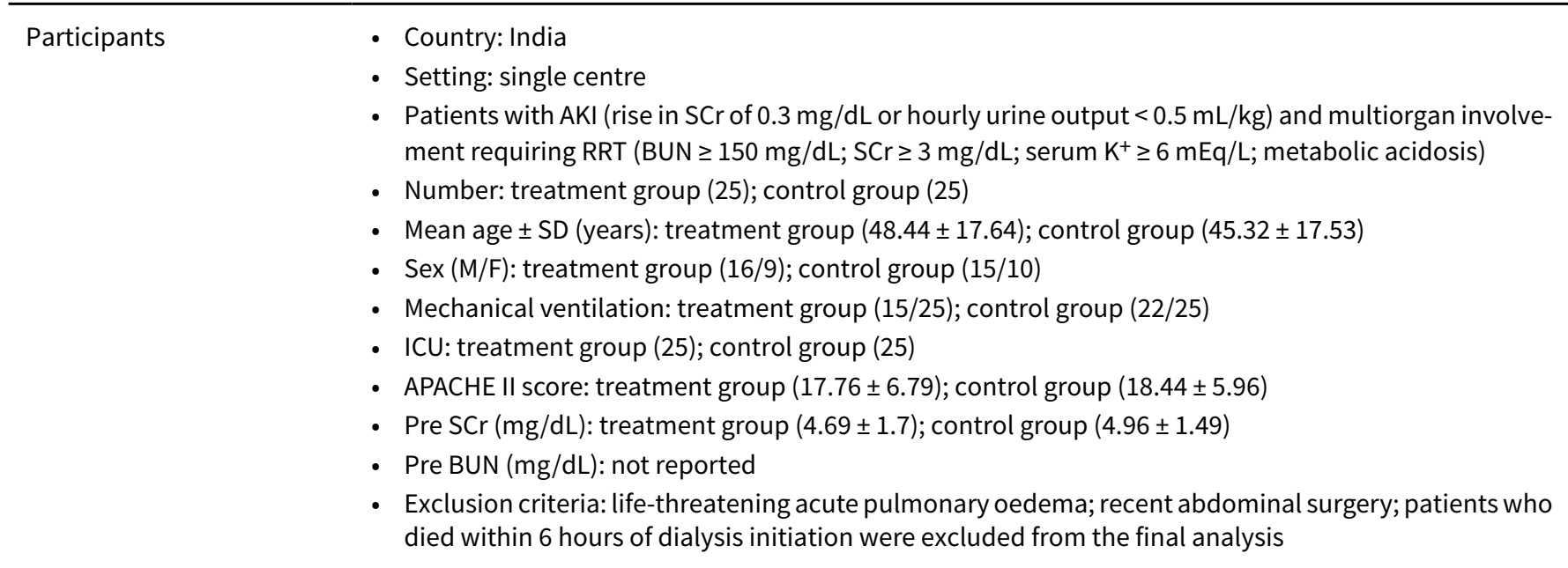

Treatment group
Interventions
CPD: $2 \mathrm{~L}$ of locally available PD fluid manually instilled using a flush-before-fill technique, with closed
drainage with dwell time of 30 minutes. Exchanges of $1 \mathrm{~L}$ were used for those with hypoxia and respi-
ratory distress. When fluid removal was inadequate, $100 \mathrm{~mL}$ sterile $25 \%$ dextrose was added to each
cycle; rigid catheter

Control group

- CVVHDF: blood pump speed was adjusted between $100 \mathrm{~mL}$ and $150 \mathrm{~mL} / \mathrm{min}$; sterile PD fluid was run in at a rate of $1 \mathrm{~L} / \mathrm{h}$. Heparin was given pre-pump, and the dose was adjusted to keep clotting time at 2.5 times normal; polysulfone haemofilter; double-lumen catheter

\begin{tabular}{|c|c|c|}
\hline Outcomes & \multicolumn{2}{|c|}{$\begin{array}{l}\text { - Death } \\
\text { - Fluid removal } \\
\text { - Duration of dialysis } \\
\text { - Correction of acidosis }\end{array}$} \\
\hline Notes & \multicolumn{2}{|c|}{ - Funding source: This study was supported in part by a research grant from Baxter Asia PD College 2005} \\
\hline \multicolumn{3}{|l|}{ Risk of bias } \\
\hline Bias & Authors' judgement & Support for judgement \\
\hline $\begin{array}{l}\text { Random sequence genera- } \\
\text { tion (selection bias) }\end{array}$ & Unclear risk & $\begin{array}{l}\text { Study was described as randomised, method of randomisation was not report- } \\
\text { ed }\end{array}$ \\
\hline
\end{tabular}


George 2011 (Continued)

\begin{tabular}{l}
$\begin{array}{l}\text { Allocation concealment } \\
\text { (selection bias) }\end{array}$ \\
\hline
\end{tabular}

Blinding of participants

High risk

Open-label study

and personnel (perfor-

mance bias)

All outcomes

$\begin{array}{lll}\text { Blinding of outcome as- } & \text { Unclear risk } & \text { Insufficient information to permit judgement } \\ \text { sessment (detection bias) }\end{array}$

sessment (detection bias)

All outcomes

\begin{tabular}{lll}
\hline $\begin{array}{l}\text { Incomplete outcome data } \\
\text { (attrition bias) } \\
\text { All outcomes }\end{array}$ & Low risk & No missing outcome data \\
\hline $\begin{array}{l}\text { Selective reporting (re- } \\
\text { porting bias) }\end{array}$ & Low risk & All expected outcomes were reported \\
\hline Other bias & Unclear risk & Part funded by Baxter Asia \\
\hline
\end{tabular}

Phu 2002

\begin{tabular}{ll}
\hline Methods & Study design: parallel RCT \\
- Study duration: 1993 to 1998 \\
- Duration of follow-up: 350 hours \\
\hline Participants & Country: Vietnam \\
- Setting: single centre \\
- patients with infection-associated AKI in an infectious-disease referral hospital in Vietnam; severe fal- \\
- ciparum malaria (48 patients) or sepsis (22 patients) were enrolled \\
- Median age, range (years): treatment group (36, 29.6 to 38.4); control group (35, 29.5 to 38.2) \\
- Sex (M/F): treatment group (27/9); control group (30/4) \\
- Mechanical ventilation: not reported \\
- ICU: treatment group (36); control group (34) \\
- APACHE II score: not reported \\
- Mean pre SCr (mg/dL): treatment group (6.3); control group (6.3) \\
- Pre BUN (mg/dL):not reported \\
- Exclusion criteria: pregnant; < 15 years of age; previously received RRT of any type during the current \\
illness
\end{tabular}

Treatment group

- PD: 2 L exchanges with a 30-minute dwell time (a total of approximately $70 \mathrm{~L} / \mathrm{d}$ ). In patients with fluid overload, hypertonic fluid was used, with an exchange consisting of $1 \mathrm{~L}$ of a solution of $15 \mathrm{~g}$ of dextrose/L and $1 \mathrm{~L}$ solution of $70 \mathrm{~g}$ of dextrose/L; rigid catheter

Control group

- HF: blood pump speed was $150 \mathrm{~mL} / \mathrm{min}$; acetate-based HF fluid was infused into the extracorporeal circuit before the haemofilter; the amount of haemofiltrate was set at approximately $25 \mathrm{~L} / \mathrm{d}$; FH-66 haemofilter; double-lumen catheter

Outcomes - Death


Phu 2002 (Continued)

- Recovery of kidney function

- Correction of acidosis

Notes

- Funding source: Supported by the Wellcome Trust of Great Britain

Risk of bias

\begin{tabular}{|c|c|c|}
\hline Bias & Authors' judgement & Support for judgement \\
\hline $\begin{array}{l}\text { Random sequence genera- } \\
\text { tion (selection bias) }\end{array}$ & Low risk & Random-number tables \\
\hline $\begin{array}{l}\text { Allocation concealment } \\
\text { (selection bias) }\end{array}$ & Low risk & Consecutively numbered, sealed, opaque, double-wrapped envelopes \\
\hline $\begin{array}{l}\text { Blinding of participants } \\
\text { and personnel (perfor- } \\
\text { mance bias) } \\
\text { All outcomes }\end{array}$ & High risk & Open-label study \\
\hline $\begin{array}{l}\text { Blinding of outcome as- } \\
\text { sessment (detection bias) } \\
\text { All outcomes }\end{array}$ & Unclear risk & Insufficient information to permit judgement \\
\hline $\begin{array}{l}\text { Incomplete outcome data } \\
\text { (attrition bias) } \\
\text { All outcomes }\end{array}$ & Low risk & No missing outcome data \\
\hline $\begin{array}{l}\text { Selective reporting (re- } \\
\text { porting bias) }\end{array}$ & Unclear risk & Insufficient information to permit judgement as study was stopped early \\
\hline Other bias & High risk & The study was stopped due to the difference in mortality rates \\
\hline
\end{tabular}

Ponce 2011

\begin{tabular}{|c|c|}
\hline Methods & $\begin{array}{l}\text { - Study design: parallel RCT } \\
\text { - Study duration: January } 2005 \text { to January } 2007 \\
\text { - Duration of follow-up: } 30 \text { days }\end{array}$ \\
\hline Participants & 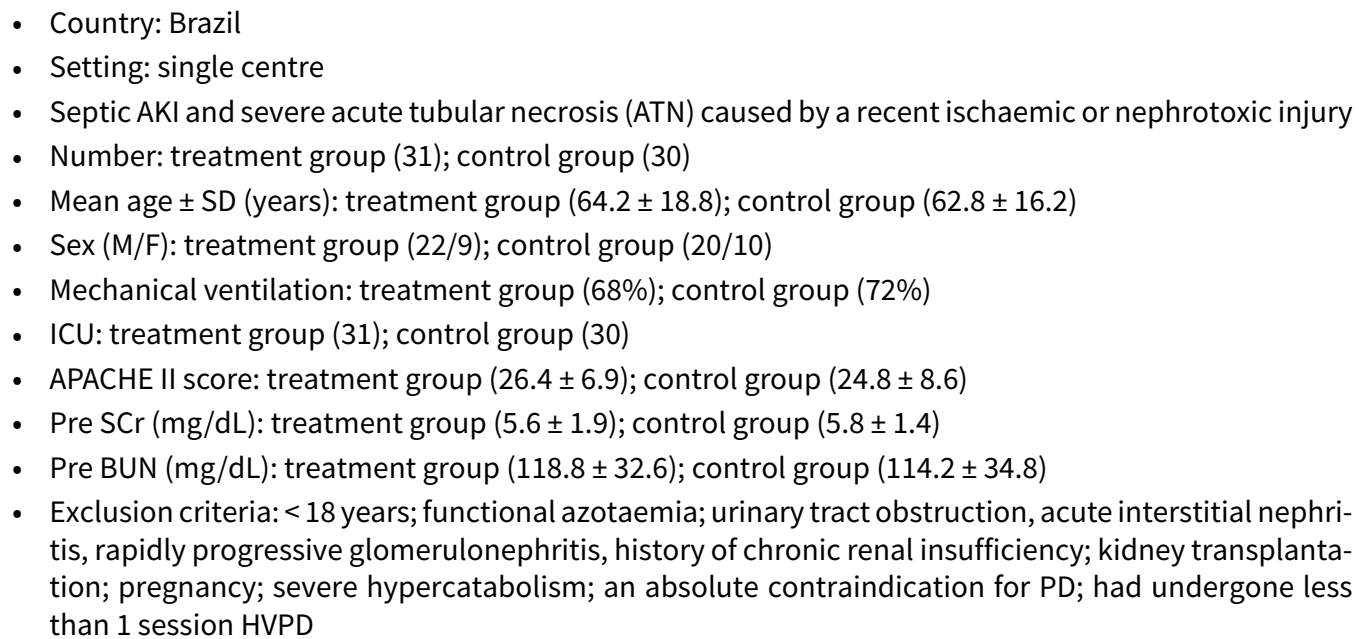 \\
\hline
\end{tabular}


Ponce 2011 (Continued)

\begin{tabular}{|c|c|}
\hline Interventions & $\begin{array}{l}\text { Treatment group } \\
\text { - HVPD: Kt/V value } 0.8 / \text { session; } 1 \text { session was } 1 \text { day ( } 24 \text { hours), and sessions were performed } 7 \text { days/wk; } \\
2 \text { L with dwell time of } 30 \text { to } 45 \text { min; flexible catheter } \\
\text { Control group } \\
\text { - HVPD: Kt/V value } 0.5 / \text { session; } 1 \text { session was } 1 \text { day ( } 24 \text { hours), and sessions were performed } 7 \text { days/wk; } \\
2 \text { L with dwell time of } 45 \text { to } 60 \text { min; flexible catheter }\end{array}$ \\
\hline Outcomes & $\begin{array}{l}\text { - Death } \\
\text { - Recovery of kidney function } \\
\text { - Kt/V } \\
\text { - Ultrafiltration } \\
\text { - Infection }\end{array}$ \\
\hline Notes & $\begin{array}{l}\text { - The study was prematurely closed because the group assigned to higher-intensity dialysis received a } \\
\text { dialysis dose lower than that prescribed } \\
\text { - Funding source: not reported }\end{array}$ \\
\hline
\end{tabular}

\section{Risk of bias}

\begin{tabular}{lll}
\hline Bias & Authors' judgement & Support for judgement \\
\hline $\begin{array}{l}\text { Random sequence genera- } \\
\text { tion (selection bias) }\end{array}$ & Unclear risk & $\begin{array}{l}\text { Study was described as randomised, method of randomisation was not report- } \\
\text { ed }\end{array}$ \\
\hline $\begin{array}{l}\text { Allocation concealment } \\
\text { (selection bias) }\end{array}$ & Low risk & Sealed envelopes \\
\hline $\begin{array}{l}\text { Blinding of participants } \\
\text { and personnel (perfor- } \\
\text { mance bias) }\end{array}$ & High risk & Open-label study \\
All outcomes & & \\
\hline
\end{tabular}

\begin{tabular}{lll}
$\begin{array}{l}\text { Blinding of outcome as- } \\
\text { sessment (detection bias) } \\
\text { All outcomes }\end{array}$ & Unclear risk & Insufficient information to permit judgement \\
\hline $\begin{array}{l}\text { Incomplete outcome data } \\
\text { (attrition bias) }\end{array}$ & Unclear risk & $\begin{array}{l}\text { 4 patients lost to follow-up; all analyses were performed according to the in- } \\
\text { tention-to-treat principle, with no imputation for missing values. Data from } \\
\text { All outcomes }\end{array}$ \\
\hline
\end{tabular}

\begin{tabular}{lll}
\hline $\begin{array}{l}\text { Selective reporting (re- } \\
\text { porting bias) }\end{array}$ & Unclear risk & All expected outcomes reported \\
\hline Other bias & Unclear risk & Study appears to be free of other biases \\
\hline
\end{tabular}

\section{Ponce 2013}

\begin{tabular}{ll}
\hline Methods & - Study design: parallel RCT \\
& - Study duration: January 2008 to January 2011 \\
& Duration of follow-up: 50 days \\
\hline Participants & Country: Brazil
\end{tabular}


Ponce 2013 (Continued)

- Setting: 2 centres

- Patients $\geq 18$ years with ATN (prolonged and profound hypotension, severe nephrotoxic drugs overdose, or excess endogenous nephrotoxic pigments) as aetiology AKI (AKNC criteria) in the ICU

- Number: treatment group (61); control group (82)

- Mean age \pm SD (years): treatment group (68 \pm 24$)$; control group $(57.2 \pm 21)$

- Sex (M/F): treatment group (45/16); control group (57/25)

- Mechanical ventilation: treatment group (83.6\%); control group (86.6\%)

- ICU: treatment group (61); control group (82)

- APACHE II score: treatment group (27.5); control group (26.7)

- Pre $\mathrm{SCr}(\mathrm{mg} / \mathrm{dL})$ : treatment group $(5.1 \pm 1.9)$; control group $(4.1 \pm 1.2)$

- Pre BUN (mg/dL): treatment group (101.5 \pm 28.9$)$; control group ( $88 \pm 8.6)$

- Exclusion criteria: severe CKD ( $\mathrm{SCr}>4 \mathrm{mg} / \mathrm{dL})$, previous chronic dialysis and kidney transplantation; very high probability of death (ATN-ISS $<0.3$ or $>0.7$ )

- HVPD: 24 h dialysis with sessions performed 7 days/wk; $2 \mathrm{~L}$ exchanges were performed with 30 to 60 min of dwell time (total of 36 to $44 \mathrm{~L} / \mathrm{d}$ and 18 to 22 exchanges/d); flexible catheter

Control group

- EHD: session lasted 6 to $8 \mathrm{~h}$ and sessions performed 6 times/wk; blood flux ranged from 150 to 200 $\mathrm{mL} / \mathrm{min}$ and dialysate flux was $300 \mathrm{~mL} / \mathrm{min}$; cellulose acetate dialysers; double-lumen catheter

\begin{tabular}{ll}
\hline Outcomes & - Death \\
- Recovery of kidney function \\
- Fluid removal \\
- Weekly Kt/V \\
- Infection
\end{tabular}

Notes Funding source: Fundacao de Amparo a` Pesquisa do Estado de Sao Paulo (FAPESP)

\section{Risk of bias}

\begin{tabular}{|c|c|c|}
\hline Bias & Authors' judgement & Support for judgement \\
\hline $\begin{array}{l}\text { Random sequence genera- } \\
\text { tion (selection bias) }\end{array}$ & Low risk & $\begin{array}{l}\text { Intervention assignment was generated by a computerised random number } \\
\text { generated with separate lists at each centre }\end{array}$ \\
\hline $\begin{array}{l}\text { Allocation concealment } \\
\text { (selection bias) }\end{array}$ & Unclear risk & Insufficient information to permit judgement \\
\hline $\begin{array}{l}\text { Blinding of participants } \\
\text { and personnel (perfor- } \\
\text { mance bias) } \\
\text { All outcomes }\end{array}$ & High risk & Open-label study \\
\hline $\begin{array}{l}\text { Blinding of outcome as- } \\
\text { sessment (detection bias) } \\
\text { All outcomes }\end{array}$ & Unclear risk & Insufficient information to permit judgement \\
\hline $\begin{array}{l}\text { Incomplete outcome data } \\
\text { (attrition bias) } \\
\text { All outcomes }\end{array}$ & Low risk & No missing outcome data \\
\hline $\begin{array}{l}\text { Selective reporting (re- } \\
\text { porting bias) }\end{array}$ & Low risk & All expected outcomes were reported \\
\hline
\end{tabular}


Ponce 2013 (Continued)

Other bias High risk
There were significant differences between PD and extracorporeal therapy in some baseline characteristics, including pre-dialysis BUN, and creatinine levels

AKI - acute kidney injury; APACHE - Acute Physiology and Chronic Health Evaluation; AKNC - Acute Kidney Network Criteria; ATN - acute tubular necrosis; BUN - blood urea nitrogen; CKD - chronic kidney disease; CPD - continuous peritoneal dialysis; CVVHDF - continuous venovenous haemodiafiltration; EHD - extended daily haemodialysis; HF - haemofiltration; DHD - daily haemodialysis; HVPD - high volume peritoneal dialysis; ICU - intensive care unit; M/F - male/female; PD - peritoneal dialysis; RCT - randomised controlled trial; RRT - renal replacement therapy; SCr - serum creatinine; SD - standard deviation; TPD - tidal peritoneal dialysis

Characteristics of excluded studies [ordered by study ID]

\begin{tabular}{ll}
\hline Study & Reason for exclusion \\
\hline Arogundade 2005 & Wrong population: mix of AKI and CKD patients \\
\hline Chitalia 2002 & Cross-over RCT; not appropriate study design for this review \\
\hline Kalra 1989 & Wrong population: mix of AKI and CKD patients \\
\hline Nand 1996 & Wrong population: mix of AKI and CKD patients \\
\hline Nand $1997 \mathrm{a}$ & Wrong intervention: PD + verapamil versus HD; verapamil not used in the HD group \\
\hline
\end{tabular}

AKi - acute kidney injury; CKD - chronic kidney disease; HD - haemodialysis; PD - peritoneal dialysis; RCT - randomised controlled trial

\section{DATA AND ANALYSES}

\section{Comparison 1. Peritoneal dialysis versus extracorporeal therapy}

\begin{tabular}{|c|c|c|c|c|}
\hline Outcome or subgroup title & No. of studies & $\begin{array}{l}\text { No. of partici- } \\
\text { pants }\end{array}$ & Statistical method & Effect size \\
\hline 1 All-cause mortality & 4 & 383 & Risk Ratio (M-H, Random, 95\% Cl) & $1.12[0.81,1.55]$ \\
\hline 2 Recovery of kidney function & 3 & 333 & Risk Ratio (M-H, Random, 95\% Cl) & $0.95[0.68,1.35]$ \\
\hline 3 Weekly delivered Kt/V & 2 & 263 & $\begin{array}{l}\text { Mean Difference (IV, Random, 95\% } \\
\mathrm{Cl} \text { ) }\end{array}$ & $-2.47[-5.17,0.22]$ \\
\hline 4 Correction of acidosis & 2 & 89 & Risk Ratio (M-H, Random, 95\% Cl) & $1.32[0.13,13.60]$ \\
\hline 5 Fluid removal & 3 & 313 & $\begin{array}{l}\text { Mean Difference (IV, Random, 95\% } \\
\mathrm{Cl} \text { ) }\end{array}$ & $-0.59[-1.19,0.01]$ \\
\hline 6 Duration of dialysis & 2 & 170 & $\begin{array}{l}\text { Mean Difference (IV, Random, 95\% } \\
\mathrm{Cl} \text { ) }\end{array}$ & $-1.01[-91.49,89.47]$ \\
\hline $\begin{array}{l}7 \text { Infectious complications } \\
\text { (catheter infection or peri- } \\
\text { tonitis) }\end{array}$ & 2 & 263 & Risk Ratio (M-H, Random, 95\% Cl) & $1.03[0.60,1.78]$ \\
\hline
\end{tabular}


Analysis 1.1. Comparison 1 Peritoneal dialysis versus extracorporeal therapy, Outcome 1 All-cause mortality.

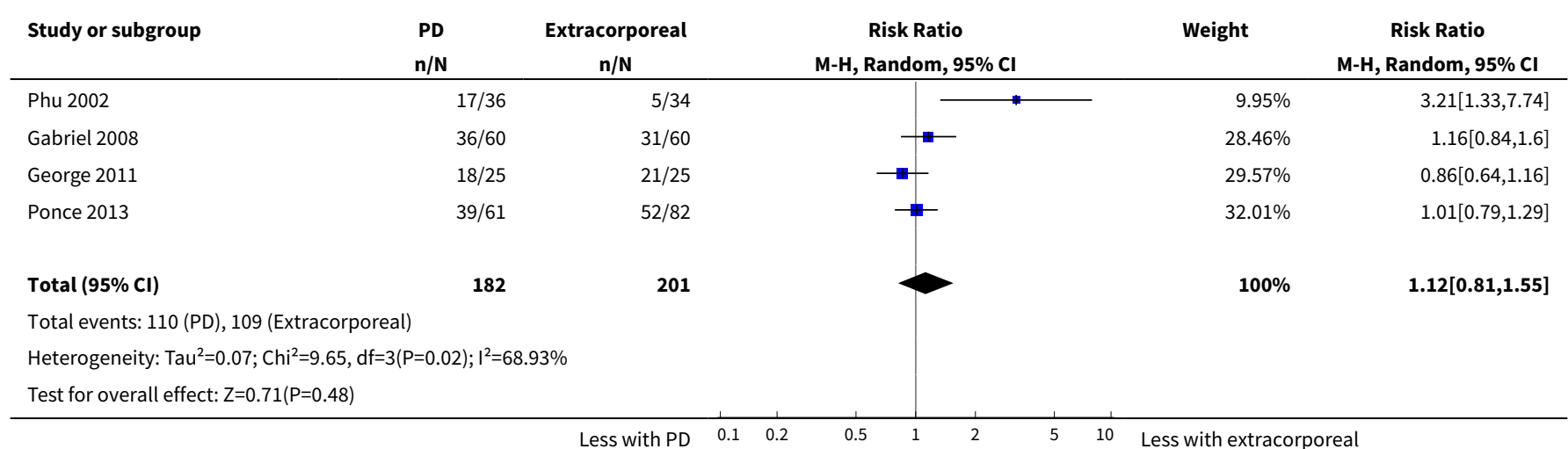

Analysis 1.2. Comparison 1 Peritoneal dialysis versus extracorporeal therapy, Outcome 2 Recovery of kidney function.

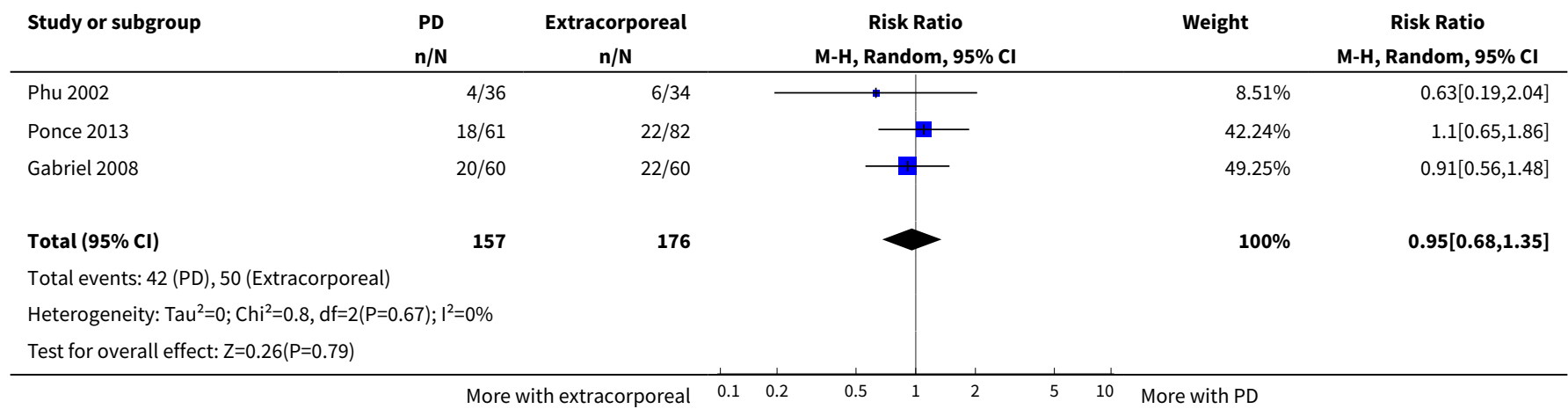

Analysis 1.3. Comparison 1 Peritoneal dialysis versus extracorporeal therapy, Outcome 3 Weekly delivered Kt/V.

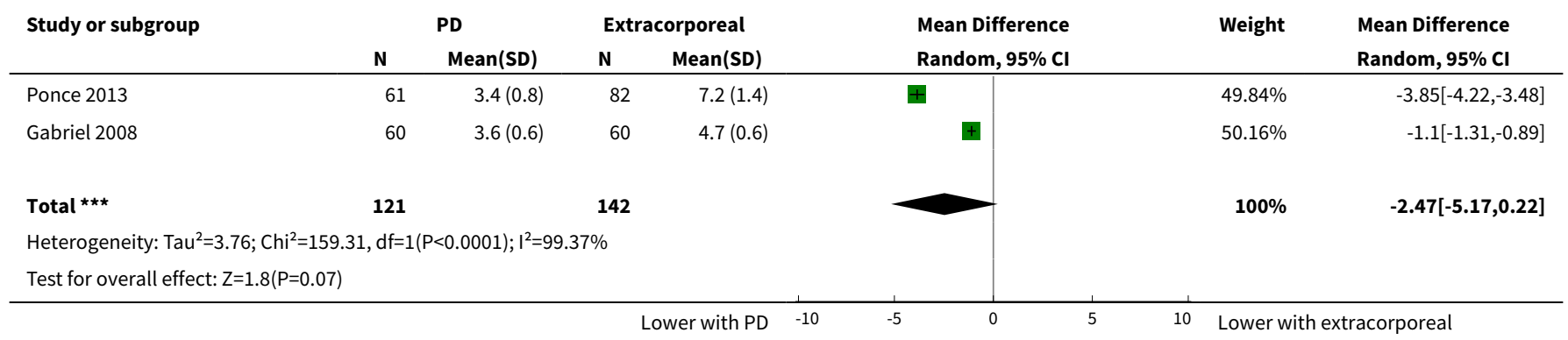


Analysis 1.4. Comparison 1 Peritoneal dialysis versus extracorporeal therapy, Outcome 4 Correction of acidosis.

\begin{tabular}{|c|c|c|c|c|c|}
\hline Study or subgroup & $\begin{array}{l}\text { PD } \\
\mathrm{n} / \mathrm{N}\end{array}$ & $\begin{array}{c}\text { Extracorporeal } \\
n / N\end{array}$ & $\begin{array}{c}\text { Risk Ratio } \\
\text { M-H, Random, } 95 \% \mathrm{Cl}\end{array}$ & Weight & $\begin{array}{c}\text { Risk Ratio } \\
\text { M-H, Random, } 95 \% \mathrm{CI}\end{array}$ \\
\hline George 2011 & $14 / 16$ & $5 / 25$ & $\longrightarrow$ & $49.22 \%$ & $4.38[1.95,9.79]$ \\
\hline Phu 2002 & $8 / 21$ & $25 / 27$ & $\rightarrow-$ & $50.78 \%$ & $0.41[0.24,0.72]$ \\
\hline Total $(95 \% \mathrm{Cl})$ & 37 & 52 & & $100 \%$ & $1.32[0.13,13.6]$ \\
\hline \multicolumn{6}{|c|}{ Total events: 22 (PD), 30 (Extracorporeal) } \\
\hline Test for overall effec & & & & & \\
\hline
\end{tabular}

Analysis 1.5. Comparison 1 Peritoneal dialysis versus extracorporeal therapy, Outcome 5 Fluid removal.

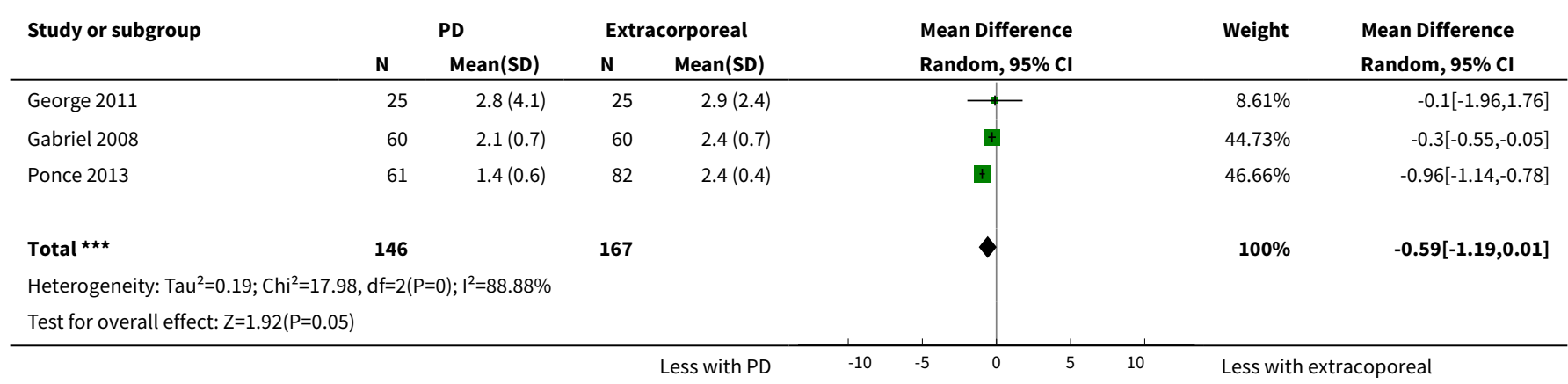

Analysis 1.6. Comparison 1 Peritoneal dialysis versus extracorporeal therapy, Outcome 6 Duration of dialysis.

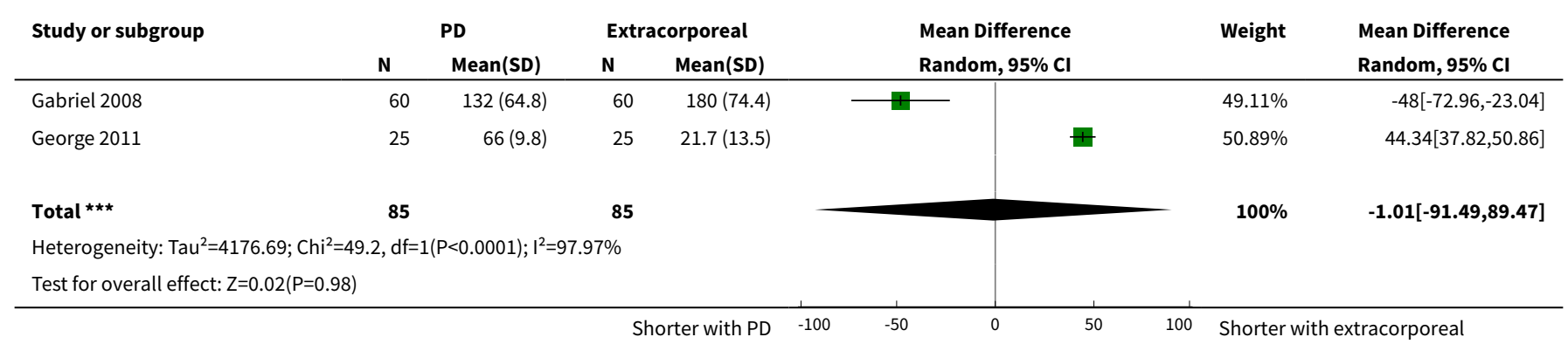

Analysis 1.7. Comparison 1 Peritoneal dialysis versus extracorporeal therapy, Outcome 7 Infectious complications (catheter infection or peritonitis).

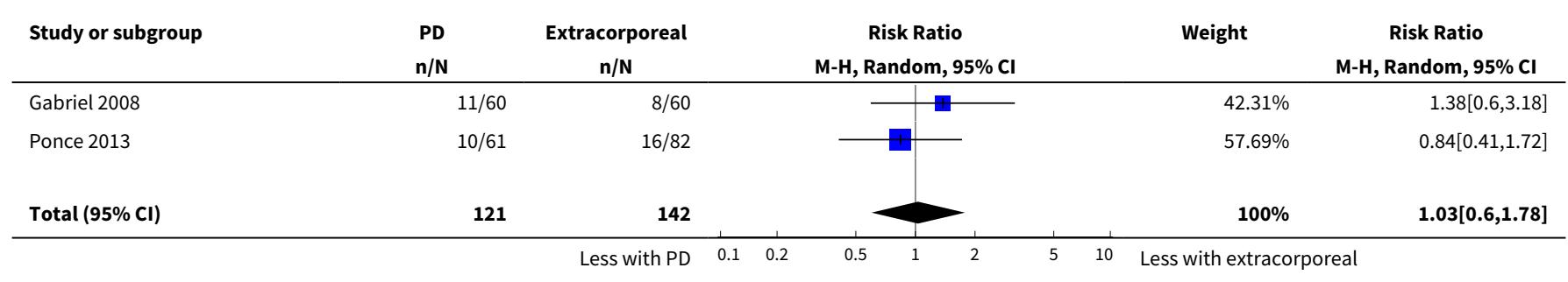




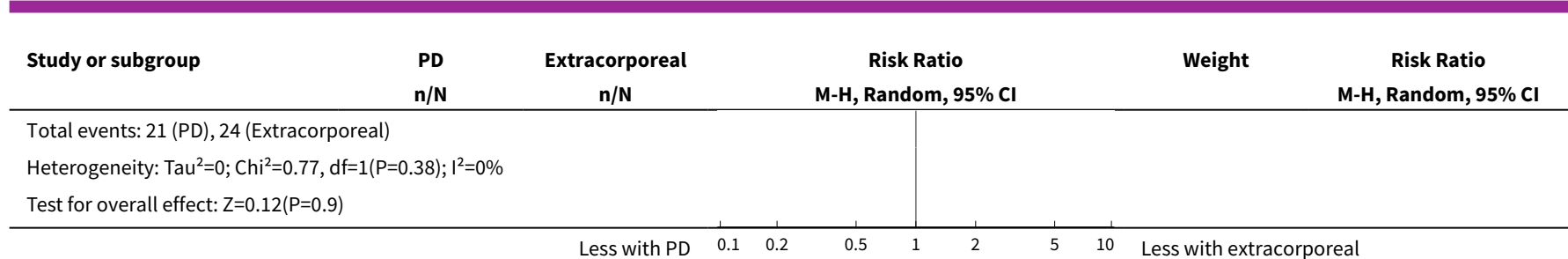

Comparison 2. High versus low intensity peritoneal dialysis

\begin{tabular}{|c|c|c|c|c|}
\hline Outcome or subgroup title & No. of studies & $\begin{array}{l}\text { No. of partici- } \\
\text { pants }\end{array}$ & Statistical method & Effect size \\
\hline 1 All-cause mortality & 1 & & Risk Ratio (M-H, Random, 95\% Cl) & Totals not selected \\
\hline 2 Recovery of kidney function & 1 & & Risk Ratio (M-H, Random, 95\% Cl) & Totals not selected \\
\hline 3 Weekly delivered Kt/V & 1 & & $\begin{array}{l}\text { Mean Difference (IV, Random, } \\
95 \% \mathrm{Cl} \text { ) }\end{array}$ & Totals not selected \\
\hline 4 Fluid removal & 1 & & $\begin{array}{l}\text { Mean Difference (IV, Random, } \\
95 \% \mathrm{CI})\end{array}$ & Totals not selected \\
\hline $\begin{array}{l}5 \text { Infectious complications } \\
\text { (catheter infection or peritoni- } \\
\text { tis) }\end{array}$ & 1 & & Risk Ratio (M-H, Random, 95\% Cl) & Totals not selected \\
\hline
\end{tabular}

Analysis 2.1. Comparison 2 High versus low intensity peritoneal dialysis, Outcome 1 All-cause mortality.

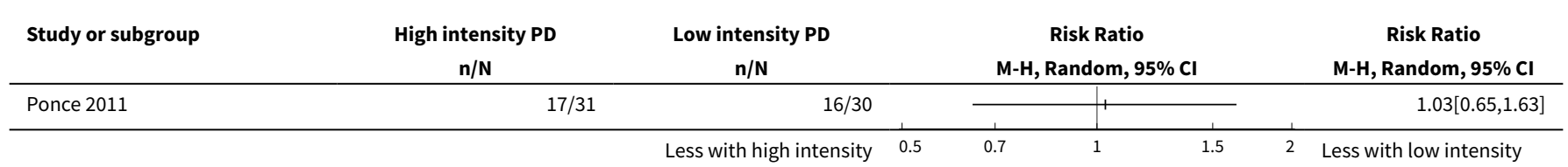

\section{Analysis 2.2. Comparison 2 High versus low intensity peritoneal dialysis, Outcome $\mathbf{2}$ Recovery of kidney function.}

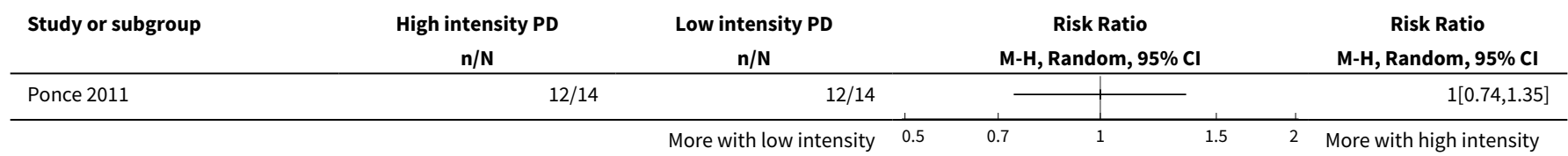

Analysis 2.3. Comparison 2 High versus low intensity peritoneal dialysis, Outcome 3 Weekly delivered Kt/V.

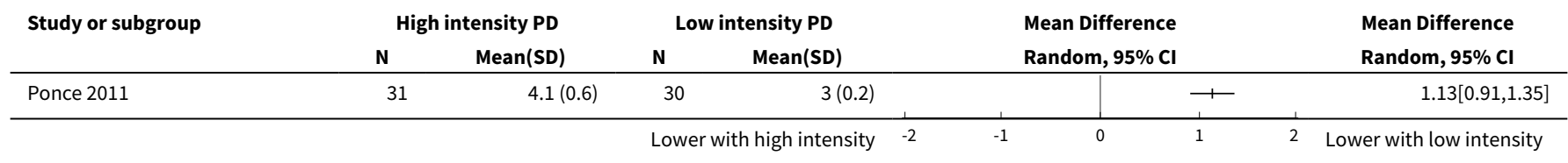


Analysis 2.4. Comparison 2 High versus low intensity peritoneal dialysis, Outcome 4 Fluid removal.

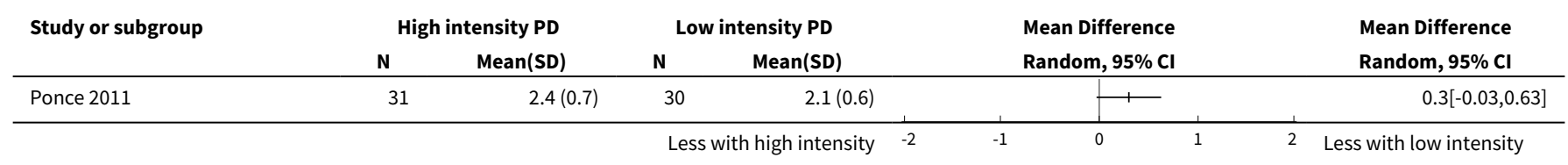

Analysis 2.5. Comparison 2 High versus low intensity peritoneal dialysis, Outcome 5 Infectious complications (catheter infection or peritonitis).

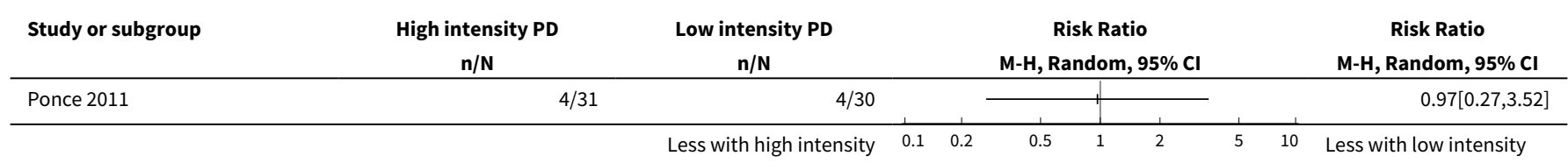

\section{APPENDICES}

\section{Appendix 1. Electronic search strategies}

\begin{tabular}{|c|c|}
\hline Database & Search terms \\
\hline \multirow[t]{9}{*}{ CENTRAL } & 1. "peritoneal dialysis":ti,ab,kw \\
\hline & 2. (CAPD or CCPD or APD):ti,ab,kw \\
\hline & 3. PD:ti,ab \\
\hline & 4. $\{$ or \#1-\#3\} \\
\hline & 5. ("acute kidney" or "acute renal"):ti,ab,kw \\
\hline & 6. "acute tubular necrosis":ti,ab,kw \\
\hline & 7. (AKI or ARI or AKF or ARF):ti,ab,kw \\
\hline & 8. $\{$ or \#5-\#7\} \\
\hline & 9. \#4 and \#8 \\
\hline \multirow[t]{10}{*}{ MEDLINE } & 1. exp Peritoneal Dialysis/ \\
\hline & 2. peritoneal dialysis.tw. \\
\hline & 3. (PD or CAPD or CCPD or APD).tw. \\
\hline & 4. or $/ 1-3$ \\
\hline & 5. exp Acute Kidney Injury/ \\
\hline & 6. (acute kidney or acute renal).tw. \\
\hline & 7. acute tubular necrosis.tw. \\
\hline & 8. (AKI or AKF or ARF or ARI).tw. \\
\hline & 9. or/5-8 \\
\hline & 10.and $/ 4,9$ \\
\hline \multirow[t]{4}{*}{ EMBASE } & 1. Peritoneal Dialysis/ \\
\hline & 2. Continuous Ambulatory Peritoneal Dialysis/ \\
\hline & 3. peritoneal dialysis.tw. \\
\hline & 4. (PD or CAPD or CCPD or APD).tw. \\
\hline
\end{tabular}



5. or/1-4
6. Acute Kidney Failure/
7. Acute Kidney Tubule Necrosis/
8. (acute kidney or acute renal).tw.
9. acute tubular necrosis.tw.
10.(AKI or ARI or AKF or ARF).tw.
$11.0 \mathrm{r} / 6-10$
12.and/5,11

\section{Appendix 2. Risk of bias assessment tool}

\section{Potential source of bias \\ Random sequence genera- tion}

\section{Assessment criteria}

Selection bias (biased allocation to interventions) due to inadequate generation of a randomised sequence

Low risk of bias: Random number table; computer random number generator; coin tossing; shuffling cards or envelopes; throwing dice; drawing of lots; minimization (minimization may be implemented without a random element, and this is considered to be equivalent to being random).

High risk of bias: Sequence generated by odd or even date of birth; date (or day) of admission; sequence generated by hospital or clinic record number; allocation by judgement of the clinician; by preference of the participant; based on the results of a laboratory test or a series of tests; by availability of the intervention.

Unclear: Insufficient information about the sequence generation process to permit judgement.

\section{Allocation concealment}

Selection bias (biased allocation to interventions) due to inadequate concealment of allocations prior to assignment

Low risk of bias: Randomisation method described that would not allow investigator/participant to know or influence intervention group before eligible participant entered in the study (e.g. central allocation, including telephone, web-based, and pharmacy-controlled, randomisation; sequentially numbered drug containers of identical appearance; sequentially numbered, opaque, sealed envelopes).

High risk of bias: Using an open random allocation schedule (e.g. a list of random numbers); assignment envelopes were used without appropriate safeguards (e.g. if envelopes were unsealed or non-opaque or not sequentially numbered); alternation or rotation; date of birth; case record number; any other explicitly unconcealed procedure.

Unclear: Randomisation stated but no information on method used is available.

\section{Blinding of participants and \\ Blinding of participants and
personnel}

Performance bias due to knowledge of the allocated interventions by participants and personnel during the study Low risk of bias: No blinding or incomplete blinding, but the review authors judge that the outcome
is not likely to be influenced by lack of blinding; blinding of participants and key study personnel ensured, and unlikely that the blinding could have been broken.

High risk of bias: No blinding or incomplete blinding, and the outcome is likely to be influenced by lack of blinding; blinding of key study participants and personnel attempted, but likely that the blinding could have been broken, and the outcome is likely to be influenced by lack of blinding.

Unclear: Insufficient information to permit judgement

\section{Blinding of outcome assess- ment}

Detection bias due to knowledge of the allocated interventions by outcome assessors.
Low risk of bias: No blinding of outcome assessment, but the review authors judge that the outcome measurement is not likely to be influenced by lack of blinding; blinding of outcome assessment ensured, and unlikely that the blinding could have been broken. 
High risk of bias: No blinding of outcome assessment, and the outcome measurement is likely to be influenced by lack of blinding; blinding of outcome assessment, but likely that the blinding could have been broken, and the outcome measurement is likely to be influenced by lack of blinding.

Unclear: Insufficient information to permit judgement

\section{Incomplete outcome data}

Attrition bias due to amount, nature or handling of incomplete outcome data.
Low risk of bias: No missing outcome data; reasons for missing outcome data unlikely to be related to true outcome (for survival data, censoring unlikely to be introducing bias); missing outcome data balanced in numbers across intervention groups, with similar reasons for missing data across groups; for dichotomous outcome data, the proportion of missing outcomes compared with observed event risk not enough to have a clinically relevant impact on the intervention effect estimate; for continuous outcome data, plausible effect size (difference in means or standardized difference in means) among missing outcomes not enough to have a clinically relevant impact on observed effect size; missing data have been imputed using appropriate methods.

High risk of bias: Reason for missing outcome data likely to be related to true outcome, with either imbalance in numbers or reasons for missing data across intervention groups; for dichotomous outcome data, the proportion of missing outcomes compared with observed event risk enough to induce clinically relevant bias in intervention effect estimate; for continuous outcome data, plausible effect size (difference in means or standardized difference in means) among missing outcomes enough to induce clinically relevant bias in observed effect size; 'as-treated' analysis done with substantial departure of the intervention received from that assigned at randomisation; potentially inappropriate application of simple imputation.

Unclear: Insufficient information to permit judgement

\section{Selective reporting}

Reporting bias due to selective outcome reporting
Low risk of bias: The study protocol is available and all of the study's pre-specified (primary and secondary) outcomes that are of interest in the review have been reported in the pre-specified way; the study protocol is not available but it is clear that the published reports include all expected outcomes, including those that were pre-specified (convincing text of this nature may be uncommon).

High risk of bias: Not all of the study's pre-specified primary outcomes have been reported; one or more primary outcomes is reported using measurements, analysis methods or subsets of the data (e.g. subscales) that were not pre-specified; one or more reported primary outcomes were not prespecified (unless clear justification for their reporting is provided, such as an unexpected adverse effect); one or more outcomes of interest in the review are reported incompletely so that they cannot be entered in a meta-analysis; the study report fails to include results for a key outcome that would be expected to have been reported for such a study.

Unclear: Insufficient information to permit judgement

\section{Other bias}

Bias due to problems not covered elsewhere in the table
Low risk of bias: The study appears to be free of other sources of bias.

High risk of bias: Had a potential source of bias related to the specific study design used; stopped early due to some data-dependent process (including a formal-stopping rule); had extreme baseline imbalance; has been claimed to have been fraudulent; had some other problem.

Unclear: Insufficient information to assess whether an important risk of bias exists; insufficient rationale or evidence that an identified problem will introduce bias.

\section{CONTRIBUTIONS OF AUTHORS}

1. Draft the protocol: Linfeng Liu, Ling Zhang, Guan J Liu, Ping Fu

2. Study selection: Linfeng Liu, Ling Zhang

3. Extract data from studies: Linfeng Liu, Ling Zhang

4. Enter data into RevMan: Linfeng Liu, Ling Zhang 
5. Carry out the analysis: Linfeng Liu, Ling Zhang, Ping Fu

6. Interpret the analysis: Linfeng Liu, Ling Zhang, Guan J Liu

7. Draft the final review: Linfeng Liu, Ling Zhang, Ping Fu

8. Disagreement resolution: Ping Fu, Guan J Liu

9. Update the review: Linfeng Liu, Ling Zhang

\section{DECLARATIONS OF INTEREST}

- Linfeng Liu: none known

- Ling Zhang: none known

- Guan J Liu: none known

- Ping Fu: none known.

\section{DIFFERENCES BETWEEN PROTOCOL AND REVIEW}

The problem of length of in-hospital stays or ICU stays, blood pressure during dialysis, and vasopressor support which might influence outcomes in AKI were not reported in most of the four included studies, leading to the lack of further analysis according to design in advance. In addition, the limited studies and patients make it difficult to conduct further subgroup analysis.

\section{NOTES}

The authors declare that they have no relevant financial interests.

\section{INDEX TERMS}

\section{Medical Subject Headings (MeSH)}

*Peritoneal Dialysis [adverse effects] [mortality] [statistics \& numerical data]; Acidosis [therapy]; Acute Kidney Injury [mortality] [*therapy]; Cause of Death; Randomized Controlled Trials as Topic; Recovery of Function; Renal Dialysis [methods]

\section{MeSH check words}

Humans 